\title{
A numerical study of mountain waves in the upper troposphere and lower stratosphere
}

\author{
A. Mahalov ${ }^{1}$, M. Moustaoui ${ }^{1}$, and V. Grubišicic ${ }^{2}$ \\ ${ }^{1}$ School of Mathematical and Statistical Sciences, Center for Environmental Fluid Dynamics, Arizona State University, \\ Tempe, USA \\ ${ }^{2}$ Department of Meteorology and Geophysics, University of Vienna, Vienna, Austria
}

Received: 21 December 2010 - Published in Atmos. Chem. Phys. Discuss.: 8 February 2011

Revised: 18 May 2011 - Accepted: 20 May 2011 - Published: 1 June 2011

\begin{abstract}
A numerical study of mountain waves in the Upper Troposphere and Lower Stratosphere (UTLS) is presented for two Intensive Observational Periods (IOPs) of the Terrain-induced Rotor Experiment (T-REX). The simulations use the Weather Research and Forecasting (WRF) model and a microscale model that is driven by the finest WRF nest. During IOP8, the simulation results reveal presence of perturbations with short wavelengths in zones of strong vertical wind shear in the UTLS that cause a reversal of momentum fluxes. The spectral properties of these perturbations and the attendant vertical profiles of heat and momentum fluxes show strong divergence near the tropopause indicating that they are generated by shear instability along shear lines locally induced by the primary mountain wave originating from the lower troposphere. This is further confirmed by results of an idealized simulation initialized with the temperature and wind profiles obtained from the microscale model. For IOP6, we analyze distributions of $\mathrm{O}_{3}$ and $\mathrm{CO}$ observed in aircraft measurements. They show small scale fluctuations with amplitudes and phases that vary along the path of the flight. Detailed comparisons between these fluctuations and the observed vertical velocity show that the behavior of these short fluctuations is due not only to the vertical motion, but also to the local mean vertical gradients where the waves evolve, which are modulated by larger variations. The microscale model simulation results show favorable agreement with in situ radiosonde and aircraft observations. The high vertical resolution offered by the microscale model is found to be critical for resolution of smaller scale processes such as formation of inversion layer associated with trapped lee waves in the troposphere, and propagating mountain waves in the lower stratosphere.
\end{abstract}

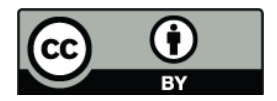

Correspondence to: A. Mahalov (mahalov@asu.edu)

\section{Introduction}

The extended region consisting of the bulk of the upper troposphere and lower stratosphere (UTLS) represents a significant challenge for numerical prediction. The combination of strong stratification and shear in this region leads to many small scale gravity wave-induced physical phenomena, which have been observed in the distributions of tracers and in the dynamical structures of the UTLS. For example, observations as well as high resolution idealized simulations have shown that waves above over-shooting moist convection may cause small scale mixing in the UTLS through local turbulence and instabilities that can be triggered during gravity wave breaking events (e.g. Wang, 2003; Moustaoui et al., 2004; Lane and Sharman, 2006). Other sources of small scales structures include mountain wave breaking (e.g. Dornbrack, 1998; Bacmeister and Schoeberl, 1989; Prusa et al., 1996; Satomura and Sato, 1999), upper tropospheric jet streams (i.e. Mahalov and Moustaoui, 2010; Joseph et al., 2004) gravity wave-critical level interactions (Lott and Teitelbaum, 1992; Teitelbaum et al., 1999; Moustaoui et al., 2004), shear instability induced by non-parallel flows (Mahalov et al., 2009) and nonlinear wave-wave interactions (Danielsen et al., 1992; Moustaoui et al., 1999, 2010).

Adequate representation in mesoscale models for these small scale phenomena requires high resolution in both the horizontal and the vertical. The lack of vertical resolution in the UTLS implies that the vertical grid spacing typically used in operational Numerical Weather Prediction (NWP) models, including mesoscale models, is insufficient to resolve all necessary vertical scales. For non-research applications as well as many research applications, NWP models are still used with a limited number of grid points in the vertical that is typically well below 100 . Usually, grid stretching is implemented to increase the vertical resolution in the boundary layer and lower tropospheric levels at the expense

Published by Copernicus Publications on behalf of the European Geosciences Union. 
of the UTLS region. This low vertical grid spacing in UTLS used in NWP models prevents the resolution of small scale dynamical processes such as wave breaking and secondary wave generation near the tropopause and in the lower stratosphere that are associated with vertically propagating mountain waves.

There are several recent numerical studies of mountain waves in real atmospheric conditions (Dornbrack et al., 2002; Serafimovich et al., 2006; Vosper and Worthington, 2002; Alexander and Teitelbaum, 2007; Doyle et al., 2005). More recently, Kirkwood et al. (2010) used radar observations and WRF model simulations to study turbulence associated with mountain waves over Northern Scandinavia. They found that WRF can accurately match the vertical wind signatures at the radar site. They also noted that WRF underestimates wind-shear and the occurrence of thin layers with very low static stability, so that vertical mixing by turbulence associated with mountain waves may be significantly more than suggested by the model. Plougonven et al. (2008) used WRF to study mountain waves over the Antarctic peninsula. There results highlighted several consequences of mountain waves in the stratosphere including forcing of the mean flow, generation of secondary inertia-gravity waves, and turbulence and mixing. The highset horizontal resolution used in the above studies was the one used in Kirkwood et al., 2010 ( $\Delta x=1 \mathrm{~km}$ and 23, 56 and 66 vertical levels); while the highest vertical resolution was used in Plougonven et al. (2008) $(\Delta x=7 \mathrm{~km}$ and 112 vertical levels).

In this study, we examine some characteristics of mountain wave dynamics in the UTLS region that were observed during the Terrain-induced Rotor Experiment (T-REX). We treat the physical and computational aspects of the physical problem with a particular emphasis on improved vertical resolution of atmospheric flows in UTLS. Toward this end we make use of the capability to refine the numerical grid in the vertical direction offered by a microscale model that is driven by WRF. The microscale model used in this study was presented in Mahalov and Moustaoui, 2009. Here we present results from high-resolution numerical simulations $(\Delta x=1 \mathrm{~km}$ and 180 vertical levels) of two T-REX Intense Observing Periods (IOP8 and IOP6), which shed new light on dynamical process in UTLS that lead to secondary generation of smallscale fluctuations induced by shear instability there (IOP8). The same simulations also offer an improved resolution of the inversion layer related to lee waves at lower tropospheric levels. Furthermore, we use an idealized model to study and explain the generation mechanism and characteristics of the small-scale fluctuations in the UTLS. For IOP6, we analyze variations of amplitudes and phases observed in $\mathrm{O}_{3}$ and $\mathrm{CO}$ along an aircraft flight. Similar analysis has been presented for the first time in Moustaoui et al. (2010). Here we extend these analysis to other legs of the flight, and we also show that although the tracer distributions is produced by vertical motions, the observed magnitude of vertical velocity does not explain alone the amplitudes found in the tracers.
The paper is organized as follows. The T-REX campaign and radiosonde observations are described in Sect. 2. The model formulation, the computational approach and the numerical experiment setup are described in Sect. 3. Section 4 presents the simulation results and the comparison with observations from T-REX IOP8. Section 5 focuses on computational results, the ability of the microscale model to resolve fine-scale dynamical processes in the UTLS, and gives a detailed study of the secondary generation mechanism of these processes. In Sect. 6, we analyze and explain relationships between $\mathrm{O}_{3}, \mathrm{CO}$ and vertical velocity observed during IOP6. Summary and conclusion are given in Sect. 7.

\section{T-REX field campaign and observations}

\section{$2.1 \quad$ T-REX field campaign}

The field campaign of the Terrain-Induced Rotor Experiment (T-REX) took place in March and April 2006 in Owens Valley in the lee of southern Sierra Nevada in eastern California (Grubišić et al., 2008). The Sierra Nevada is a nearly two-dimensional mountain range that is about $640 \mathrm{~km}$ long and $60-130 \mathrm{~km}$ wide with gentle upwind and steep $(\approx 30 \mathrm{de}-$ grees) lee side slopes. The southern part of the range is the tallest and steepest; the ridge line there has an average altitude of $3.500 \mathrm{~m}$ and a number of peaks above $4 \mathrm{~km}$, including the highest peak in the 48 contiguous states (Mt. Whitney $4,418 \mathrm{~m}$ ). The T-REX target region was located in the central part of Owens Valley, near town of Independence, where a dense cluster of ground-based in situ and remote-sensing instruments was installed.

In this study, we exploit data on terrain-induced gravitywave structures obtained within UTLS during IOP 6 (24 March, 20:00 UTC-26 March, 05:00 UTC) and IOP 8 (31 March, 11:00 UTC-1 April, 17:00 UTC). There were two instrument platforms in T-REX that collected in situ data in UTLS. In addition to the NSF/NCAR G-V (HIAPER) aircraft, the measurements in the UTLS region were obtained by vertical profiling with radiosondes and dropsondes. Most of these were GPS sondes for obtaining high-resolution vertical profiles of temperature, relative humidity as well as wind speed and direction. The radiosonde systems were deployed both on the upstream and downstream sides of the Sierra Nevada, including one mobile and two stationary systems on the upwind side, and two stationary systems in Owens Valley downstream (near $36.78^{\circ} \mathrm{N}, 118.17^{\circ} \mathrm{W}$ ). The stationary system at Three Rivers, CA $\left(36.49^{\circ} \mathrm{N}, 118.84^{\circ} \mathrm{W}\right)$, on the upwind side of the Sierra Nevada, was deployed by the Air Force Research Laboratory (AFRL).

For the analysis of gravity wave properties and the model verification in this study, we exploit radiosonde data from TREX IOP 8 and G-V aircraft data from IOP 6. 
$\theta(\mathrm{K})$

200340480620760900
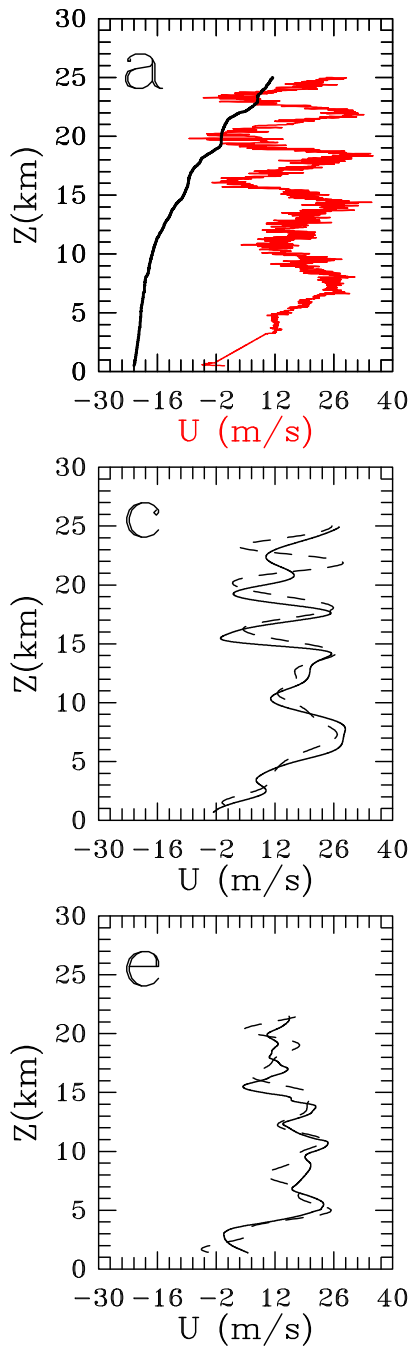

$\theta(\mathrm{K})$

200340480620760900
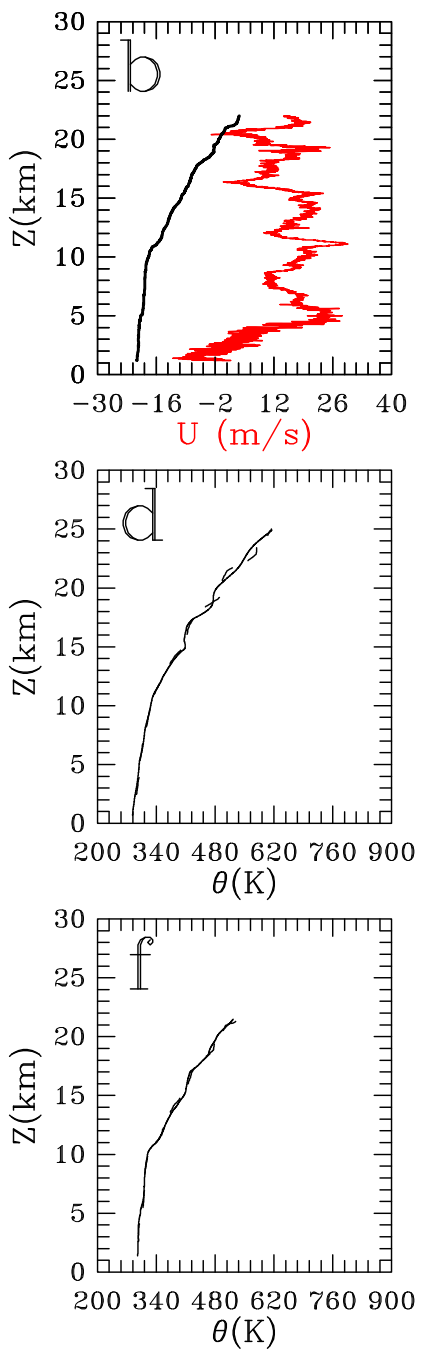

Fig. 1. Vertical profiles of potential temperature (black) and eastward wind component (red) from GPS radiosondes launched from (a) Three Rivers $\left(36.49^{\circ} \mathrm{N}, 118.84^{\circ} \mathrm{W}\right)$ at $1000 \mathrm{UTC}$, and (b) Owens Valley $\left(36.78^{\circ} \mathrm{N}, 118.17^{\circ} \mathrm{W}\right)$ on 1 April 2006, 08:00 UTC. Vertical profiles of (c) eastward wind component, and (d) potential temperature from the radiosonde observations (dashed) and microscale model simulation (solid). The observed profiles are smoothed versions of the radiosonde profiles from (a). (e) and (f) are the same as (c) and (d) but for the radiosonde data shown in (b).

\subsection{IOP 8 observations}

Figure 1a shows vertical profiles of potential temperature and eastward wind component obtained by the AFRL radiosonde launched on 1 April 2006, 10:05 UTC from the Three Rivers site during T-REX IOP 8 . The sonde crossed the Sierra Nevada during its ascent while drifting to the north-east. By the time the sonde reached the lower-stratospheric levels, it

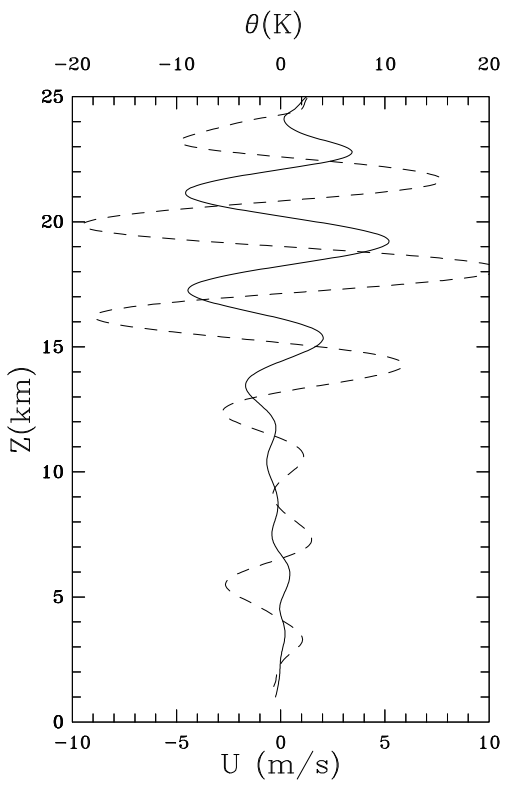

Fig. 2. Vertical profiles of potential temperature (solid) and eastward wind component (dashed) perturbations obtained by applying a band pass filter to the profiles shown in Fig. 1a. The band pass filter spans the range of wavelengths between 3 and $5 \mathrm{~km}$.

was located over the Owens Valley target region (Fig. 3d). Strong mountain wave activity is evident in these profiles, with a large amplitude wave in the lower stratosphere with a dominant vertical wavelength between 3 and $4 \mathrm{~km}$ as seen by the radiosonde along its slanted path. Figure 2 shows the fluctuations of potential temperature and eastward wind after filtering the profiles presented in Fig. 1a. These fluctuations were obtained by using a band-pass non-recursive filter in the range between 3 and $5 \mathrm{~km}$ in wavelength. This filter uses a Kaiser window to avoid Gibbs phenomenon (Hamming, 1983). The potential temperature and the wind perturbations have large amplitudes and are in quadrature of phase. Based on the polarization relations for gravity waves, which are given by $-i \hat{\omega} \frac{\theta^{\prime}}{\bar{\theta}}=\frac{N^{2} k}{g m} u^{\prime}$ (Fritts and Alexander, 2003), the latter suggests that these perturbations are gravity waves. We will show in Sect. 4 that these waves are generated by mountains. The apparent vertical wavelength from the radiosonde profile is around $3.8 \mathrm{~km}$. This wavelength reflects both the vertical and horizontal variations in the wave field. As the balloon follows a slanted path through mountain waves with phases lines that are tilted upstream, the radiosonde encounters two equivalent phase surfaces after a vertical displacement that is less than the actual vertical wavelength of the mountain wave (Teitelbaum et al., 1996; Wang et al., 2009). Assuming the waves are hydrostatic, i.e. that the horizontal wavelength is much larger than the vertical wavelength, the latter can be estimated from $\lambda_{z}=2 \pi U / N$. The mean wind and stability ( $U$ and $N$ ) are estimated from the profiles shown in Fig. 1a after smoothing out all fluctuations with 


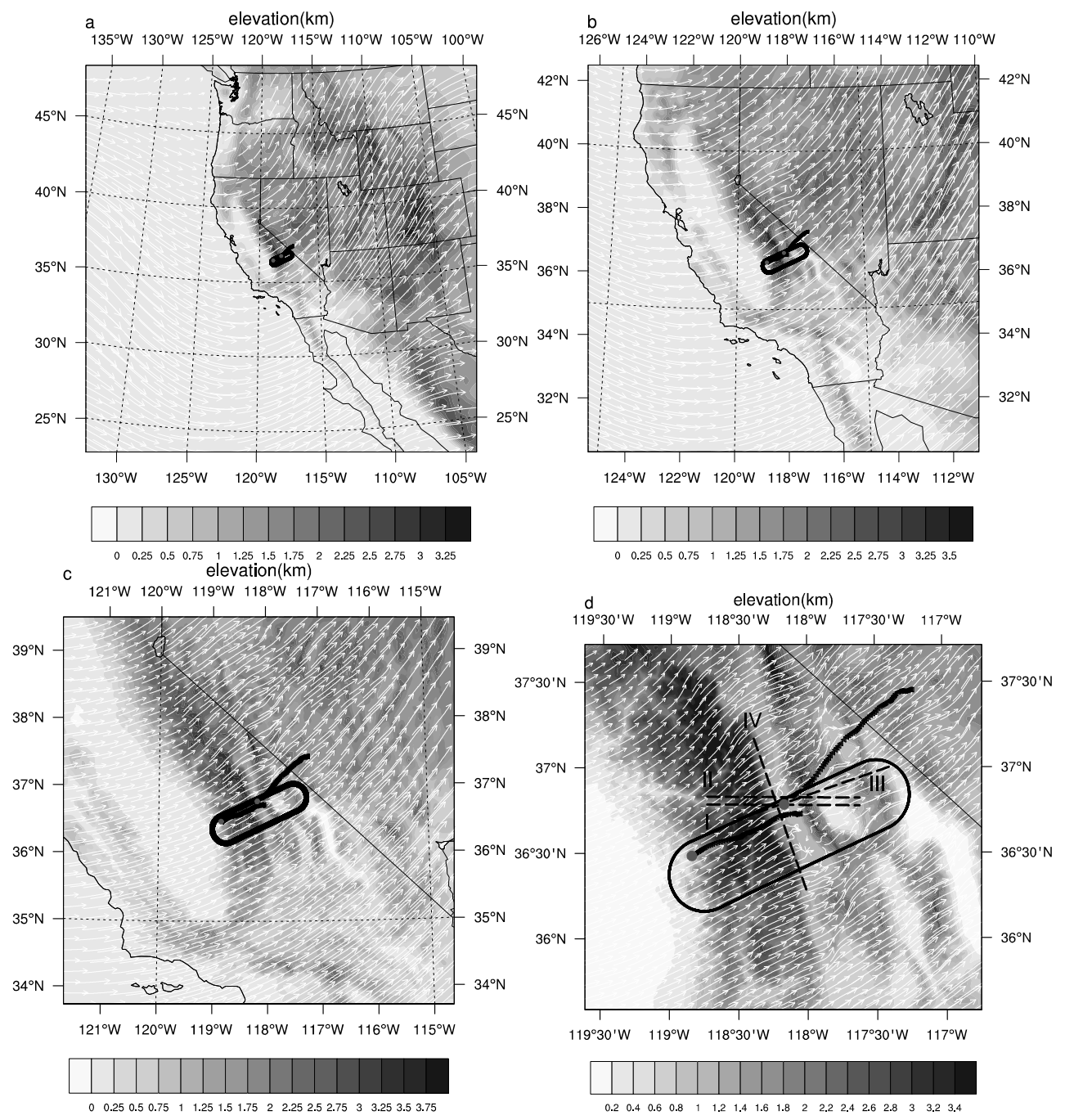

Fig. 3. Topography and domains of the WRF and microscale model simulations. (a)-(c) WRF domains with the horizontal grid spacing of (a) $27 \mathrm{~km}$, (b) $9 \mathrm{~km}$, and (c) $3 \mathrm{~km}$. (d) The microscale model domain with the grid spacing of $1 \mathrm{~km}$. Also shown are the simulated wind vector fields near the tropopause $(z=12 \mathrm{~km})$ on 1 April 2006, 08:00 UTC (white vectors). Solid bold curves and grey dots indicate the trajectories and launching sites of the two radiosondes from Fig. 1a-b. Elliptical curve is the racetrack flight path of the G-V aircraft (cf. Fig. 15). Dashed lines I, II, III, IV in panel (d) indicate the baselines of vertical cross sections shown in Figs. 5, 7, 8, and 10.

wavelengths shorter than $10 \mathrm{~km}$, and averaging the resulting profiles of $U$ and $N$ between $15 \mathrm{~km}$ and $22 \mathrm{~km}$ in height. This gives a vertical wavelength of $4.5 \mathrm{~km}$, which is comparable to the wavelength obtained from the simulation results discussed in Sect. 4.

Similar structures in the stratosphere are also evident in the sounding that was launched from Owens Valley, on the downstream side of the Sierra Nevada on 1 April, 08:00 UTC (Fig. 1b). The downstream sounding features a sharper definition of tropopause around $11 \mathrm{~km} \mathrm{m.s.l.} \mathrm{due} \mathrm{to} \mathrm{mountain-}$ wave-induced changes to stability. In addition, these profiles reveal pronounced perturbations at low- to mid-tropospheric levels such as a wind reversal near the ground with negative values around $-5 \mathrm{~m} \mathrm{~s}^{-1}$ near $1.8 \mathrm{~km}$ m.s.l., and wind increasing above this altitude and reaching approximately $25 \mathrm{~m} \mathrm{~s}^{-1}$ around $5 \mathrm{~km}$ m.s.l. The potential temperature is well mixed at low levels with a relatively strong inversion found around $5 \mathrm{~km}$ m.s.l.

\section{Computational method and numerical setup}

The simulations presented in this study use WRF and microscale models. The WRF model is run first, and the output from its innermost nest is used as a coarse grid input for the microscale model. The WRF fields are archived with a frequency of $30 \mathrm{~min}$. The output from WRF is then interpolated in time and space, the latter in both the horizontal and vertical directions, to provide initial and boundary conditions for the microscale model run that is carried out separately. The 
use of the microscale model is motivated by the fact that the version of the WRF model used in this study does not allow vertical grid refinement.

\subsection{WRF simulations}

The Weather Research and Forecasting (WRF) model is a next generation mesoscale NWP model (Skamarock and Klemp, 2008). It is the first fully compressible conservativeform nonhydrostatic atmospheric model suitable for both research and weather prediction applications. All WRF simulations presented in this study use version WRF3.1 of the Advanced Research WRF (WRF-ARW). Among the important upgrades included in version 3 is the implementation of a new scheme to handle gravity wave reflections near the top of the domain (Klemp et al., 2008). The new technique, based on implicit absorbing layer placed near the top of the domain, is effective and robust.

The WRF simulations were performed with three nested domains using two-way nesting. The three WRF domains have the horizontal grid spacing of 27,9 and $3 \mathrm{~km}$. The number of vertical sigma pressure levels used in all three WRF domains is 61 , with a non-uniform distribution in the vertical. The purpose of the non-uniform distribution was to achieve an improved resolution near the tropopause and in the lower stratosphere. The pressure at the top is $p_{\text {top }}=10$ $\mathrm{hPa}$. Numerical simulations were performed for two events that correspond to IOP 6 and IOP 8 of the T-REX campaign. The three WRF domains were selected based on the location and timing of the observations.

For T-REX IOP 8 case, the WRF simulations were conducted for the period from 31 March, 00:00 UTC to 2 April 2006, 00:00 UTC. Figure 3a-c show the three WRF domains used for this case study. The domains are centered at $\left(36.49^{\circ} \mathrm{N}, 118.8^{\circ} \mathrm{W}\right)$. Also shown in Fig. $3 \mathrm{a}-\mathrm{c}$ are the topography and the simulated wind field on 1 April 2006, 08:00 UTC at $z=12 \mathrm{~km}$. The winds are predominantly south-westerly over the Sierra Nevada. The thick black curves in Fig. 3 represent the trajectories of two IOP 8 radiosondes from Fig. 1a-b. The black ellipsoidal curve indicates the racetrack pattern of the NSF/NCAR G-V research aircraft in IOP 6.

The WRF simulations were initialized with the highresolution data provided by the European Centre for Medium-Range Weather Forecasts (ECMWF) global spectral model T799L91. This model has a very high resolution with a spectral triangular truncation at horizontal wave number 799, corresponding approximately to a grid spacing of $25 \mathrm{~km}$ in the horizontal, and 91 vertical levels up to $0.01 \mathrm{hPa}$ ( $80 \mathrm{~km}$ altitude). Figure 4 shows the synoptic-scale conditions near the T-REX target area on 1 April 2006 during TREX IOP 8 from the parent WRF domain. Strong southwesterly winds associated with a deformed jet are nearly perpendicular to the orientation of the Sierra Nevada creating conditions favorable for mountain wave generation and strong

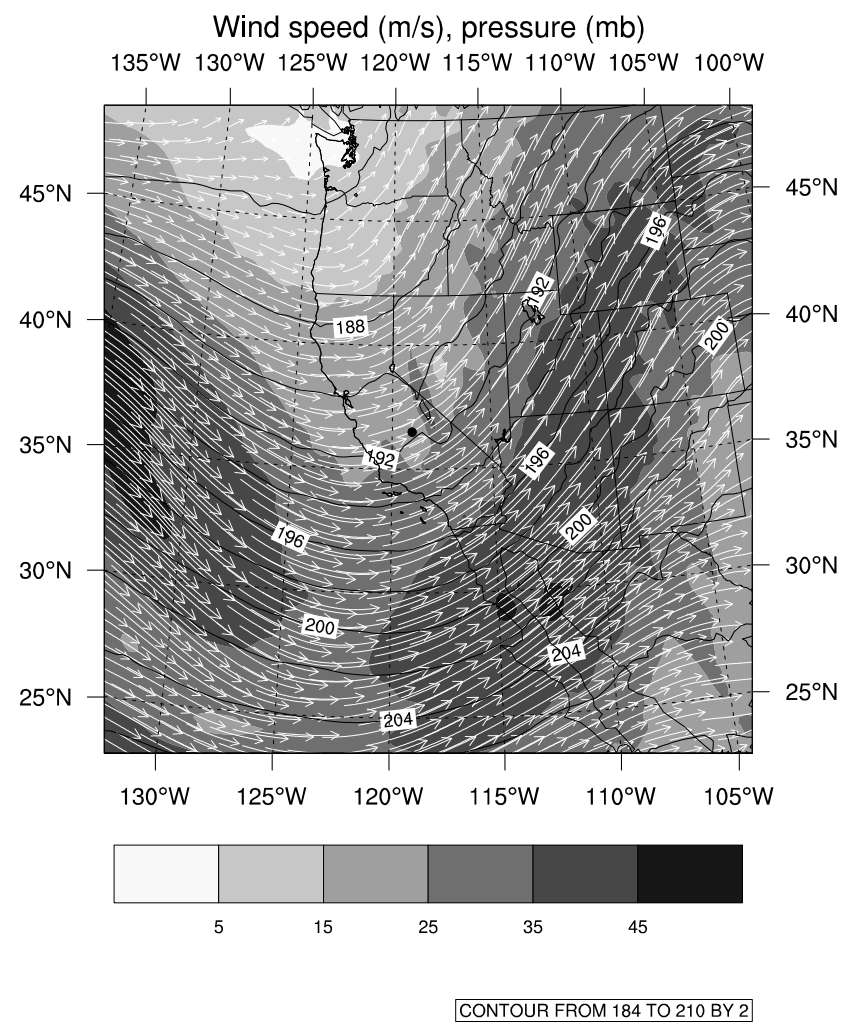

Fig. 4. Wind speed (shaded, $\mathrm{ms}^{-1}$ ), pressure (contours, hPa) and streamlines at $z=12 \mathrm{~km}$ from the largest domain of the WRF simulation on 1 April 2006, 08:00 UTC.

wave dynamics in the stratosphere (Grubišić and Billings, 2008).

For the IOP 6 case study, the WRF simulation was conducted for the period from 24 March 2006, 12:00 UTC to 26 March 2006, 12:00 UTC using the same domains as in the IOP 8 case. The synoptic-scale conditions during T-REX IOP 6 were similar to those described above for IOP 8.

\subsection{Microscale model}

The microscale code used in this study solves the 3-D, fullycompressible, non-hydrostatic equations for atmospheric dynamics. To ensure consistency with WRF, these equations are cast in conservative form and are formulated using a terrain-following pressure coordinate (Laprise, 1992) denoted by $\eta$ and defined as: $\eta=\left(p_{d h}-p_{d h t}\right) / \mu_{d}$ where $\mu_{d}=p_{d h s}-p_{d h t}$, and $\mu_{d}$ represents the mass of dry air in the column and $p_{d h}, p_{d h t}$ and $p_{d h s}$ represent, respectively, the hydrostatic pressure of the dry atmosphere, and the hydrostatic pressure at the top and bottom of the dry atmosphere. The formulated moist equations are:

$$
\begin{aligned}
& \partial_{t} U+(\nabla \cdot V u)_{\eta}+\left(\alpha / \alpha_{d}\right)\left(\alpha_{d} \partial_{x} p+\partial_{\eta} p \partial_{x} \phi\right)=F_{U} \\
& \partial_{t} V+(\nabla \cdot V v)_{\eta}+\left(\alpha / \alpha_{d}\right)\left(\alpha_{d} \partial_{y} p+\partial_{\eta} p \partial_{y} \phi\right)=F_{V}
\end{aligned}
$$




$$
\begin{aligned}
\partial_{t} W+(\nabla \cdot \mathbf{V} w)_{\eta}-g\left[\left(\alpha / \alpha_{d}\right) \partial_{\eta} p-\mu_{d}\right] & =F_{W} \\
\partial_{t} \Theta+(\nabla \cdot \mathbf{V} \theta)_{\eta} & =F_{\theta} \\
\partial_{t} \mu_{d}+(\nabla \cdot \mathbf{V})_{\eta} & =0 \\
\partial_{t} \phi+\mu_{d}^{-1}\left[(\mathbf{V} \cdot \nabla \phi)_{\eta}-g W\right] & =0 \\
\partial_{t} Q_{m}+\left(\nabla \cdot \mathbf{V} q_{m}\right)_{\eta} & =F_{Q_{m}}
\end{aligned}
$$

In these equations $\boldsymbol{v}(u, v, w)$ is the physical velocity vector, $\theta$ is the potential temperature, $p$ is the pressure, $g$ is the acceleration of gravity, $\phi=g z$ is the geopotential, $(U, V, W, \Omega, \Theta)=\mu_{d}(u, v, w, \omega, \theta)$, where $\omega=d \eta / d t$ is the vertical velocity in the computational space, and $\mathbf{V}=(U, V, \Omega)$ is the coupled velocity vector. The right-handside terms $F_{U}, F_{V}, F_{W}$, and $F_{\theta}$ represent forcing terms arising from model physics, subgrid-scale mixing, spherical projections, and the earth's rotation. The microphysics parametrization uses the Thompson scheme (Thompson et al., 2004). The eddy viscosities used for subgrid-scale mixing are computed from the prognostic turbulent kinetic energy (TKE) equation. The prognostic TKE equations is integrated, including terms for advection, heat flux sources, Reynolds stress sources, diffusion and dissipation (Lilly, 1966). The eddy mixing coefficient $K_{m}$ is the related to the turbulence kinetic energy $(e)$ through the expression: $K_{m}=C_{k} l e^{0.5}$, where $l$ is a measure of the grid scale and $C_{k}=0.12$. The above governing equations are solved together with the diagnostic equation for coupled dry inverse density,

$\partial_{\eta} \phi=-\alpha_{d}$

and the diagnostic relation for the full pressure (vapor plus dry air) $p=p_{0}\left(R_{d} \Theta_{m} / p_{0} \alpha_{d}\right)^{\gamma}$. In these equations, $\alpha_{d}$ is the coupled inverse density of the dry air $\left(\alpha_{d}=\mu_{d} / \rho_{d}\right)$ and $\alpha$ is the coupled inverse density taking into account the full parcel density $\alpha=\alpha_{d}\left(1+q_{v}+q_{c}+q_{r}+q_{i}+\ldots\right)^{-1}$ where $q_{*}$ are the mixing ratios (mass per mass of dry air) for water vapor, cloud, rain, ice, etc. Additionally, $\Theta_{m}=\Theta\left(1+\left(R_{v} / R_{d}\right) q_{v}\right) \approx \Theta\left(1+1.61 q_{v}\right)$, and $Q_{m}=\mu_{d} q_{m} ;$ $q_{m}=q_{v}, q_{c}, q_{i}, \ldots$.

The details of the microscale code and the implicit relaxation used for the boundary conditions are described in Mahalov and Moustaoui (2009). The implicit relaxation boundary scheme consists of progressively constraining the main prognostic variables of the limited area model to match the corresponding values from the coarse grid model in a 9point large relaxation zone next to the boundary. The microscale nest uses $259 \times 241$ grid points in the horizontal ( $1 \mathrm{~km}$ grid spacing) and 181 vertical levels up to $10 \mathrm{hPa}$. Figure $3 \mathrm{~d}$ shows the topography and the simulated wind at $12 \mathrm{~km}$ altitude within the microscale domain on 1 April 2006, 08:00 UTC. As in the WRF simulation, the wind directions are predominantly SW. We note a very smooth relaxation of the wind field at the boundaries of the microscale domain.

\section{Simulation results and comparison with observations for T-REX IOP 8}

\subsection{Comparison between simulations and observations}

The comparison between the vertical profiles of potential temperature and the eastward wind component obtained by the radiosonde measurements on 1 April 2006, 08:00 UTC during T-REX IOP 8 and those simulated by the microscale model is shown in Fig. 1c-d. The observed profiles are the ones from Fig. 1a, except that the observed wind profile was filtered to remove fluctuations with wavelength shorter than $1.5 \mathrm{~km}$. The simulated profiles are interpolated in time and space to the slanted path of the radiosonde. The measured and simulated soundings are fairly close except for some phase errors. The observed and simulated wind profiles show a vertical wavelength of $3.8 \mathrm{~km}$, and an amplitude of $10 \mathrm{~m} / \mathrm{s}$. Evidently, the microscale model is able to reproduce the fine vertical structure and amplitude of the horizontal wind variation observed by the radiosonde. We note that the apparent vertical wavelength of $3.8 \mathrm{~km}$, reproduced by the microscale model, is smaller than the actual vertical wavelength $(4.5 \mathrm{~km})$ and reflects both the vertical and horizontal variations along the slanted path of the balloon. Both the potential temperature and wind speed profiles show the well-developed waves and nearly adiabatic layers collocated at the same altitudes (e.g., $z=16 \mathrm{~km}$ ). Another comparison of the observed and simulated soundings from IOP 8 is provided in Fig. 1e-f; this one for the sonde launched from Owens Valley on 1 April 2006, 08:00 UTC (cf. Fig. 1b). As with the profile in Fig. 1c, the observed wind profile was filtered to remove small-scale fluctuations. In both of these cases, the potential temperature profile shows an inversion layer around $5 \mathrm{~km}$ and high stability at the tropopause.

\subsection{Simulation results}

Figure 5a-d show longitude-altitude cross sections of potential temperature and eastward wind component on 1 April 2006, 08:00 UTC from the three WRF domains and the microscale nest. These vertical cross-sections show clear evidence of mountain waves, with high activity primarily occurring on the downstream side of the Sierra Nevada. The phase lines of potential temperature exhibit upstream tilt with height that is typical of mountain waves. Comparison of the WRF solutions at different horizontal resolutions shows a progressive increase in detail in the simulated potential temperature and velocity fields with increasing horizontal resolution (Fig. 5a-c). Comparing the solutions from the finest WRF mesoscale nest to that obtained by the microscale model (Fig. 5d) reveals fine-scale structures in the latter that are not resolved within the WRF domains despite the flow becoming better resolved as the horizontal resolution is increased within the successive WRF nested domains. 


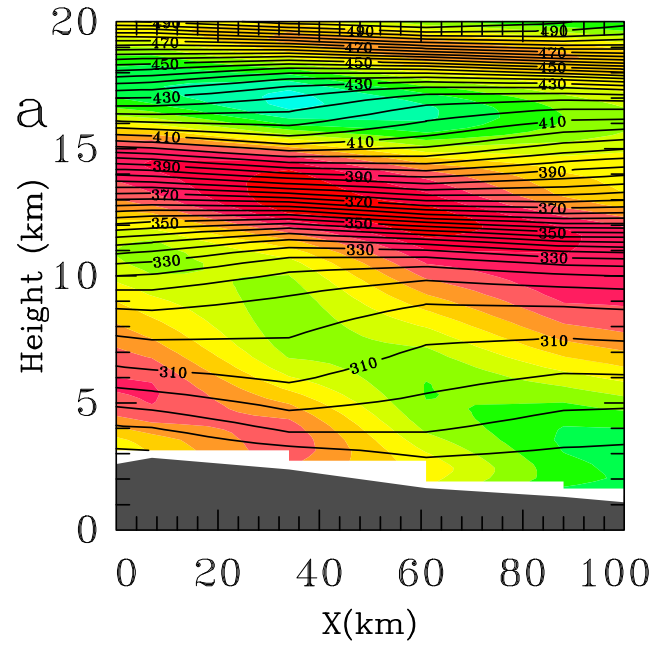

Eastward wind $(\mathrm{m} / \mathrm{s})$
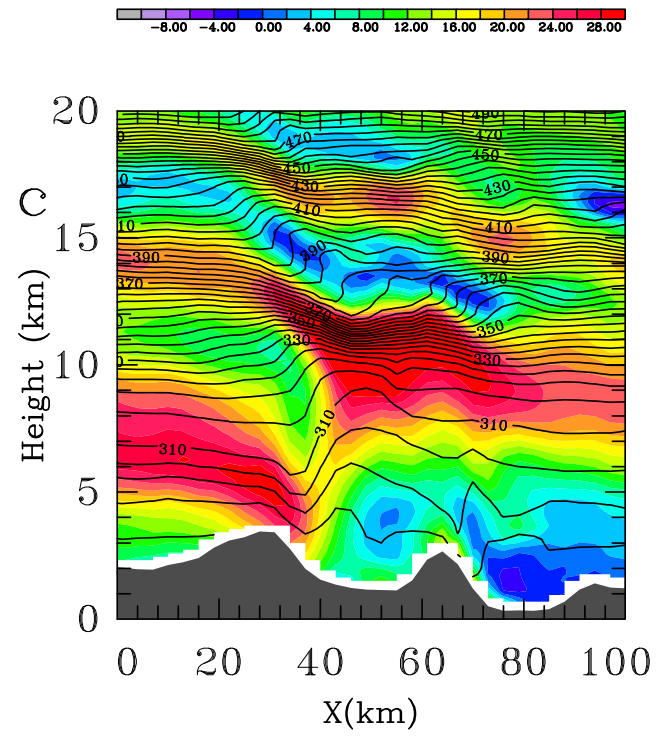

Eastward wind $(\mathrm{m} / \mathrm{s})$

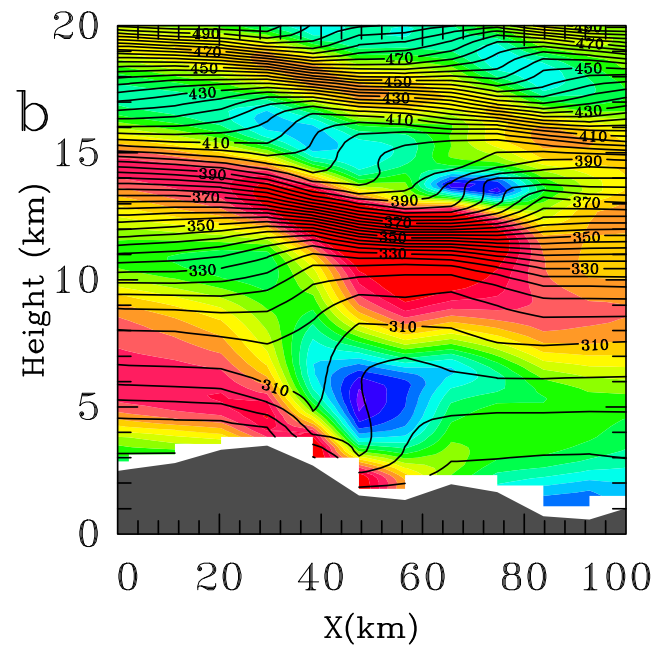

Eastward wind $(\mathrm{m} / \mathrm{s})$

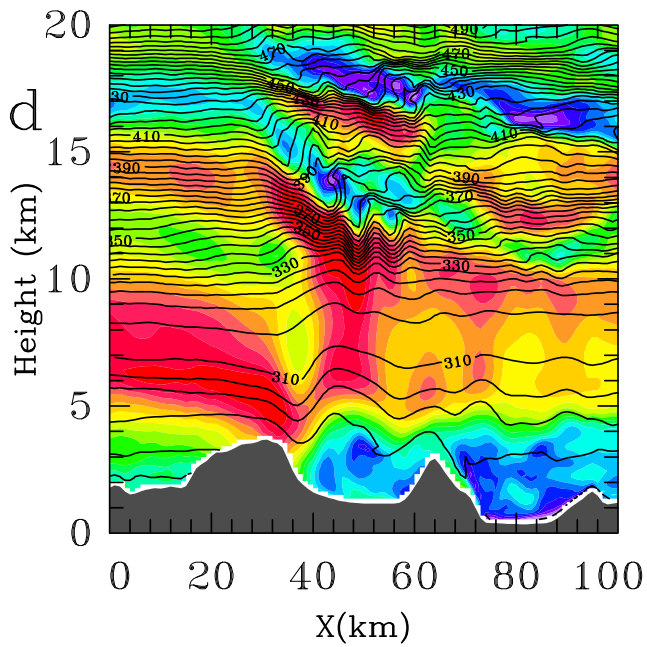

Eastward wind $(\mathrm{m} / \mathrm{s})$

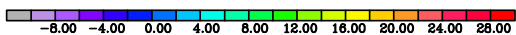

Fig. 5. Vertical cross-sections of potential temperature (contours, K) and eastward wind component (color, $\mathrm{m} \mathrm{s}^{-1}$ ): (a)-(c) from the three WRF domains, and (d) microscale nest on 1 April 2006, 08:00 UTC. The baseline of cross-sections in (a)-(d) is dashed line I in Fig. 3d. The numbers on the horizontal axes indicate the distance relative to $\left(36.79^{\circ} \mathrm{N}, 118.73^{\circ} \mathrm{W}\right)$.

In addition to improvements in the resolution of fine-scale structures of potential temperature and velocity in the UTLS region, noticeable differences are also evident in the flow structure at low levels over Owens Valley, where the microscale model results show a well developed trapped lee wave (Fig. 5d). The trapped lee wave is characterized by vertical phase lines (between $x=40 \mathrm{~km}$ and $x=60 \mathrm{~km}$ in Fig. 5d), and its amplitude is particularly pronounced around the inversion layer near $5 \mathrm{~km}$, which is also evident in the valley soundings (cf. Fig. 1b). The east-west component of wind shows negative values near the ground (easterly wind), as well as strong shear and positive (westerly) wind near the inversion layer. This clockwise circulation, together with a nearly uniform well-mixed potential temperature field within the valley are indicative of the presence of a rotor (Grubišić and Billings, 2007). An overall similar structure is evident in the finest WRF nest result (Fig. 5c); however, the finescale detail within the rotor region is not well resolved and the inversion layer around $5 \mathrm{~km}$ is not well developed over the valley. The Scorer parameter (Fig. 6) calculated from the 


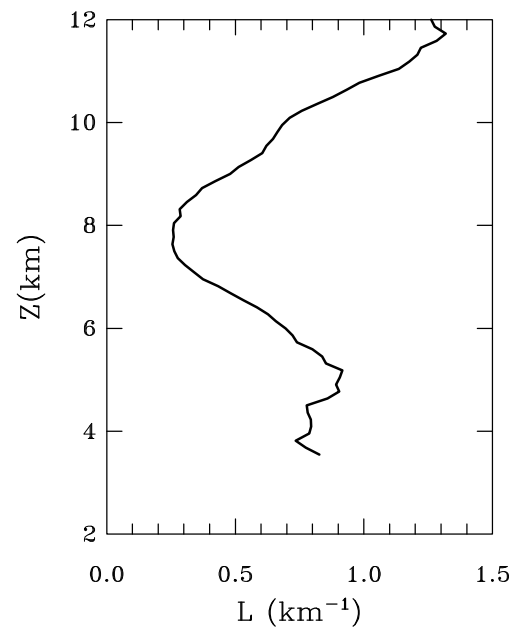

Fig. 6. Vertical profile of the Scorer parameter calculated from model from the microscale model simulation at 08:00 UTC on 1 April 2006. This profile is averaged over Owens Valley.

microscale simulations results shows a decrease with the altitude between the $5 \mathrm{~km}$ and $8 \mathrm{~km}$, which allow for formation of trapped lee waves.

Figure 7a-b show vertical cross sections of potential temperature and horizontal wind speed across and along Owens Valley on 1 April 2006, 08:00 UTC. The horizontal wind speed shown in these figures is the velocity component transverse to the NNW-SSE-oriented valley axis. The cross-valley vertical sections show flow field due to trapped lee waves in the lower troposphere downwind of the Sierra Nevada, and a vertically propagating mountain wave with vertical wavelength around $4.5 \mathrm{~km}$ in UTLS above Owens Valley (Fig. 7a). The alternate layers of high and low stability in the stratosphere, with two low stability pockets around $13 \mathrm{~km}$ and $18 \mathrm{~km} \mathrm{~m} . s .1$. , are induced by the vertically propagating mountain wave. The attendant wind field variations follow the same pattern with weak winds in the low stability regions and strong winds in the high stability zones. These relationships are similar to those observed in the radiosonde profiles in Fig. 1a.

Although the Sierra Nevada is known for its nearly twodimensional profile near Owens Valley, the flow is not uniform in the along-valley direction (Fig. 7b). A striking feature in this respect is an apparent cold dome structure in potential temperature field, in between two zones of strong cross-valley flow reaching close to the valley floor (Fig. 7b). This along-valley variation of the flow appears to be related to the lee-side terrain of the Sierra Nevada and the attendant position of the leading edge of the lee wave and rotor. Where the along-valley cross section cuts closer to the high terrain $(1<y<20 \mathrm{~km}$ in Fig. $7 \mathrm{~b})$, we find evidence of downslope winds in a lee-wave trough: a shallow stablystratified layer of strong winds reaching down to the ground, topped by weaker stratification and weaker winds aloft. In the middle portion of this vertical cross-section, where the Sierra Nevada terrain curves slightly away from line IV in Fig. $3 d(30<y<70 \mathrm{~km}$ in Fig. $7 b)$, the vertical cross section cuts through the lee wave close to its crest and the rotor zone underneath: the flow near the ground is weak, in places even reversed, and potential temperature well mixed; on top of this there is a pronounced inversion and strong flow in the troposphere above $5 \mathrm{~km} \mathrm{~m}$.s.l. In the stratosphere, where the flow is dominated by the vertically propagating mountain wave, there is less variation of the flow structure in the along-valley direction; nevertheless, small-scale three-dimensional variation of the flow is evident there as well (Fig. 7b).

In Fig. $7 \mathrm{c}-\mathrm{d}$ the same cross-sections are shown at 06:00 UTC. While the overall structure of the flow at these two times is similar, a closer inspection reveals differences both at the lower tropospheric levels as well as in the UTLS region. At 06:00 UTC, the inversion around $5 \mathrm{~km} \mathrm{~m}$.s.l. is not nearly as well developed as it is at 08:00 UTC. The concentration of the lower-tropospheric stability near the inversion is even more evident when comparing the profiles of vertical gradients of potential temperature at lower levels above Owens Valley between the two times (not shown).

In the UTLS region above Owens Valley $(20<x<40 \mathrm{~km}$ in Fig. 7c), we note the presence of secondary wave-like fluctuations that are collocated with strong vertical shear of the horizontal wind. The wind shear owes its origin to the primary mountain wave. Using observations obtained by the NSF/NCAR G-V aircraft during T-REX, Smith et al. (2008) found short waves in the lower stratosphere. They conjecture that these waves are associated with secondary wave generation but were not able to identify their generation mechanism. The structure of the short perturbations found in Fig. 7c is more evident in Fig. 8a, which provides a zoom view of potential temperature and vertical velocity in this region. The perturbations are reflected in the vertical velocity field as well, giving rise to strong updrafts and downdrafts reaching up to $\pm 5-7 \mathrm{~m} \mathrm{~s}^{-1}$. The horizontal wavelength of these small-scale perturbations is close to $7 \mathrm{~km}$ - too short to be directly excited by topography. Furthermore, there is not much evidence for such short waves at tropospheric levels below $10 \mathrm{~km}$. In the next section, we examine the properties and generation mechanisms of these small-scale perturbations in more detail.

\section{Characteristics and generation mechanism of short fluctuations in UTLS during IOP 8}

In this section we examine in more detail the characteristics and generation mechanism of short fluctuations in UTLS illustrated in Figs. 7 and 8 described in Sect. 4. As noted earlier, these fluctuations form in regions of high vertical wind shear due to the primary mountain wave. Before focusing on the physical properties of these short-wavelike fluctuations we note that the vertical grid refinement appears critical 

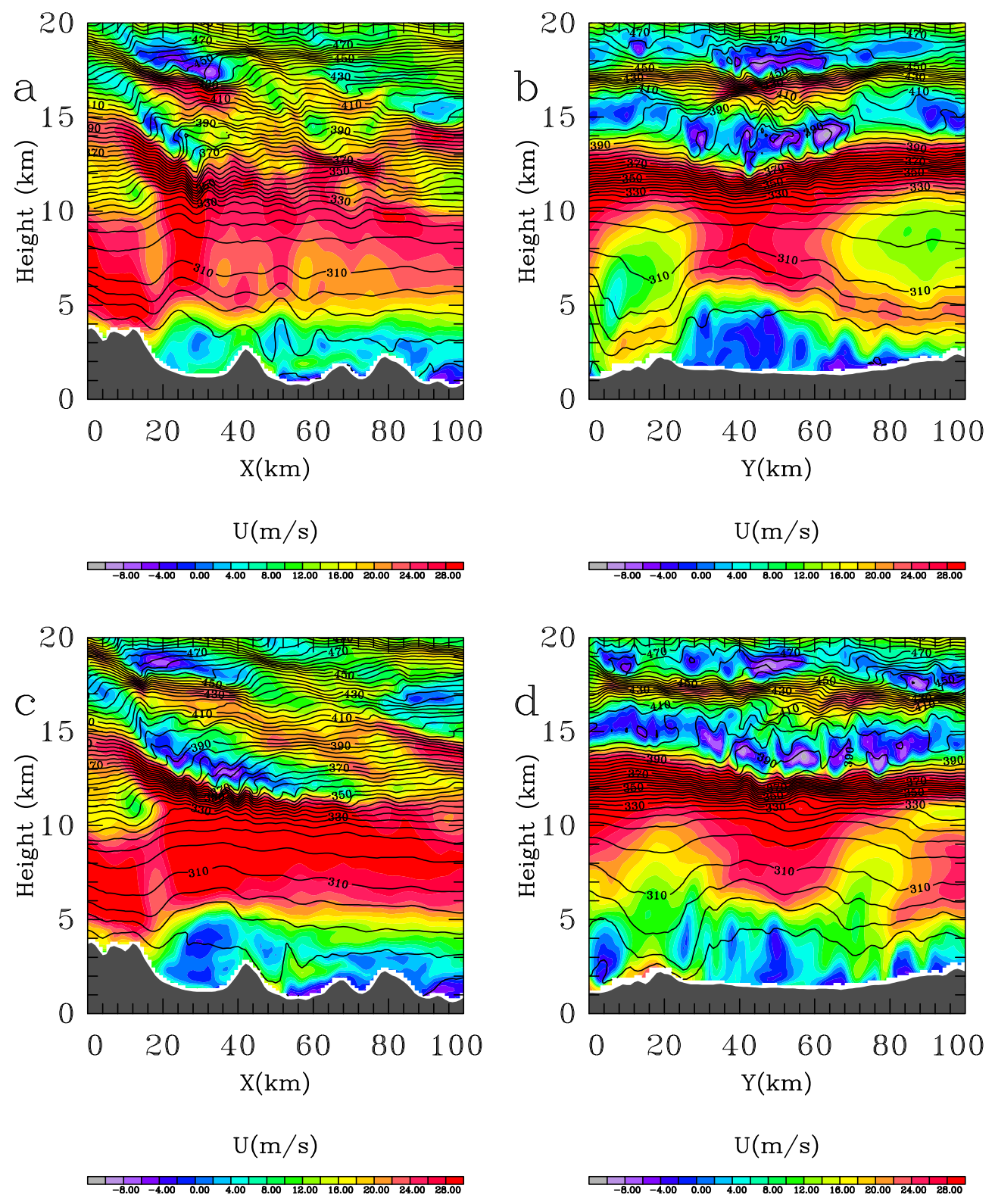

Fig. 7. (a) Cross- and (b) along-valley vertical cross-sections of potential temperature (K) and horizontal wind component transverse to the valley axis (color, $\mathrm{ms}^{-1}$ ) from the microscale model domain on 1 April 2006, 08:00 UTC. The bases of these cross sections are dashed lines III and IV in Fig. 3d. The horizontal axes X and Y indicate the distance relative to locations $\left(36.70^{\circ} \mathrm{N}, 118.50^{\circ} \mathrm{W}\right)$ and $\left(36.29^{\circ} \mathrm{N}\right.$, $\left.118.01^{\circ} \mathrm{W}\right)$. Panels (c) and (d) show the same as (a) and (b) except on 1 April 2006, 06:00 UTC .

for resolving these fine-scale features. In Fig. 8b the same zoomed cross section is shown as in Fig. 8a but with results from the microscale simulation in which the grid refinement was applied in the horizontal direction only. The absence of the fine-scale features in Fig. 8b (no vertical grid refinement) is striking. This shows that the vertical grid refinement is critical for resolving small-scale structures and for numerically simulating dynamical processes in UTLS that lead to their generation.

\subsection{Characteristics of short fluctuations}

Figure 9 shows co-spectra of the eastward wind component and vertical velocity simulated by the microscale model. These co-spectra were calculated at each vertical level along a horizontal segment of $L=100 \mathrm{~km}$ in length over the valley (a portion of dashed line II in Fig. 3d). The two curves in Fig. 9 show vertically averaged co-spectra within UTLS $(10 \mathrm{~km}<z<14 \mathrm{~km})$ and at mid- and upper-tropospheric levels $(6<z<10 \mathrm{~km})$. The mountain wave dominates the spectra 


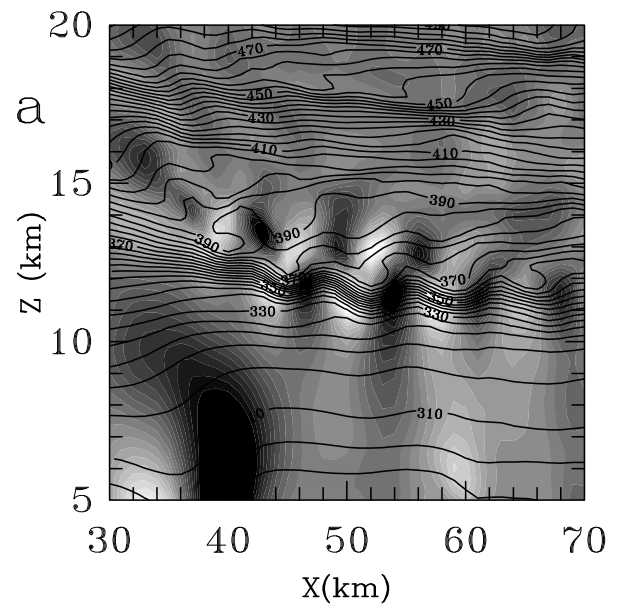

W $(\mathrm{m} / \mathrm{s})$

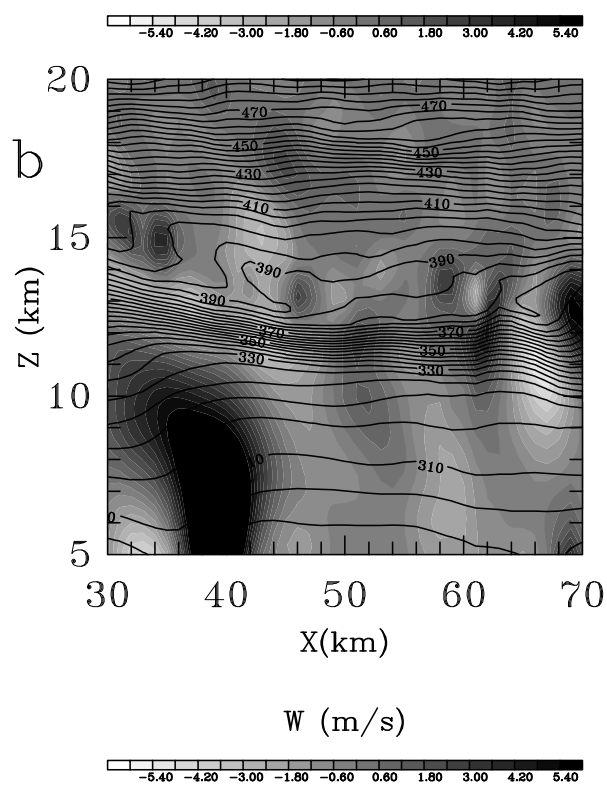

Fig. 8. Zoomed view of potential temperature (contours, K) and vertical velocity (grey scale, $\mathrm{m} \mathrm{s}^{-1}$ ) within the UTLS from a portion of the vertical cross-section shown in Fig. 7c. Shown are the results on 1 April 2006, 06:00 UTC from two microscale model simulations with the horizontal grid spacing of $1 \mathrm{~km}$ : (a) with vertical grid refinement, (b) without vertical grid refinement.

in both regions. The co-spectra show a peak at horizontal wavenumber $k L / 2 \pi=2$, which corresponds to the horizontal wavelength of $\lambda \approx 50 \mathrm{~km}$. Around this wavelength the co-spectra are negative. Negative values of the horizontal and vertical velocity co-spectra are expected for upward propagating mountains waves in the westerly mean flow. The UTLS co-spectrum shows another peak at shorter wavelengths around $\lambda \approx 7.4 \mathrm{~km}$, which corresponds to wavenumber $k L / 2 \pi=13.5$. This peak is positive indicating a reversal in sign of the co-spectrum. The short-wavelength cospectrum peak is not present at lower levels; this confirms

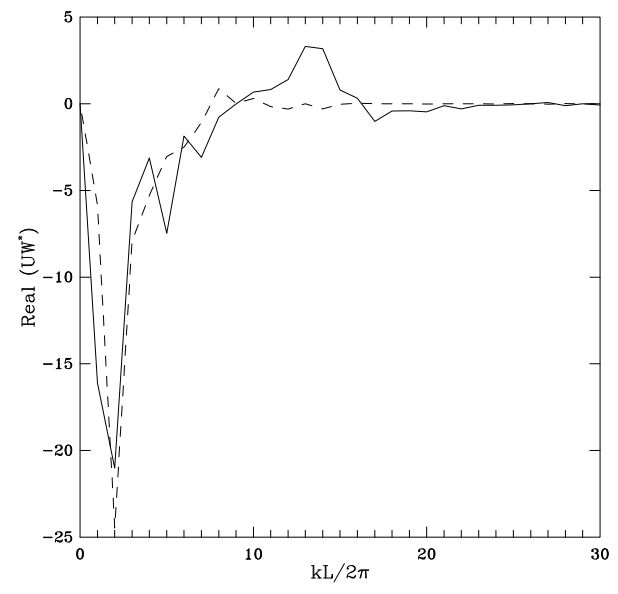

Fig. 9. Co-spectra of $(\mathrm{U}, \mathrm{W})$ fields simulated by the microscale model on 1 April 2006, 06:00 UTC. The averaged co-spectra for the UTLS region ( $10 \mathrm{~km}<z<14 \mathrm{~km}$; solid) and the upper troposphere $(6 \mathrm{~km}<z<10 \mathrm{~km}$; dashed) are shown as a function of normalized horizontal wave number $k L / 2 \pi$. The spectra at different altitudes were computed along the $100 \mathrm{~km}$-long segment of dashed line II in Fig. 3d.

that these short-wavelike fluctuations do not originate from the ground.

Based on these co-spectra, the model fields were filtered at each level to remove the primary mountain wave. The band pass filter spans a range of wavelengths between 5 and $12 \mathrm{~km}$. The filtered fields are then used to calculate the local distribution of momentum flux associated with the short-wavelike fluctuations. This spatial distribution is obtained by locally averaging the momentum flux within a running window of $24 \mathrm{~km}$ in width. Figure 10 shows the vertical cross section of momentum flux associated with the short-wavelike fluctuations. The positive momentum flux associated with the short-wavelike fluctuations is confined between $z=11 \mathrm{~km}$ and $z=13 \mathrm{~km}$ in the UTLS region (Fig. 10). No wave-like activity of this type is found below $z=10 \mathrm{~km}$. In the horizontal, these fluctuations are found above Owens Valley only $(40 \mathrm{~km}<x<60 \mathrm{~km})$. The vertical profile of momentum flux averaged over the valley (Fig. 11) is positive with strong divergence near $z=12 \mathrm{~km}$ - the level at which the primary mountain wave induces high vertical shear of the horizontal wind (Fig. 7c). The vertical profile of heat flux, also shown in Fig. 11, displays negative values and strong divergence near the same altitude. This shows that the short-wavelike fluctuations are not gravity waves. If the short fluctuations in the UTLS were trapped gravity waves, both the heat and momentum fluxes should be equal to zero. Instead, the vertical profiles of heat and momentum fluxes associated with these short fluctuations are such that the flux divergences tend to mix the potential temperature and to reduce the shear induced by the primary wave $\left(\partial u / \partial t=-1 / \rho \times \partial\left(\overline{\rho u^{\prime} w^{\prime}}\right) / \partial z\right.$, $\left.\partial \theta / \partial t=-1 / \rho \times \partial\left(\overline{\rho \theta^{\prime} w^{\prime}}\right) / \partial z\right)$. 


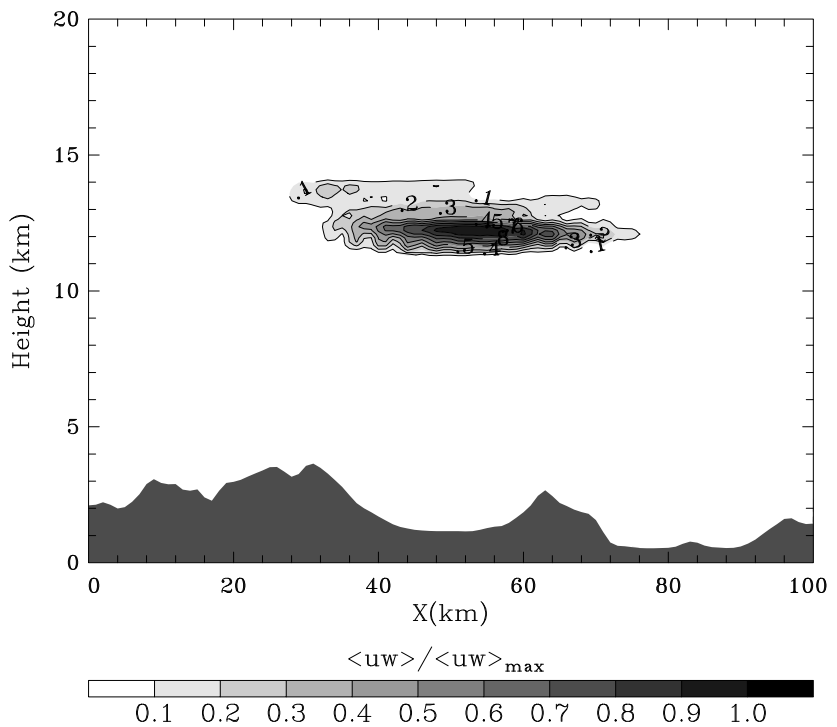

Fig. 10. Vertical cross-section of momentum flux due to shortwavelike fluctuations with horizontal wavelength in the range between 5 and $12 \mathrm{~km}$. The momentum flux was computed from the microscale model fields on 1 April 2006, 06:00 UTC. For details of the computation see text. The base of the cross-section is dashed line II of Fig. 3d. The horizontal axis indicates the distance with respect to location $\left(36.83^{\circ} \mathrm{N}, 118.73^{\circ} \mathrm{W}\right)$.

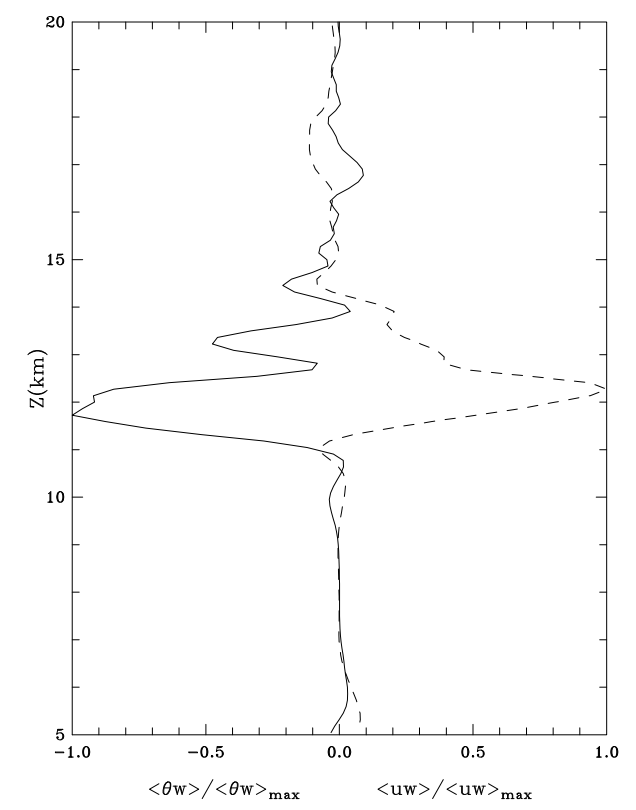

Fig. 11. Vertical profiles of momentum (dashed) and heat (solid) fluxes due to short-wave fluctuations in the UTLS region from the microscale model simulation on 1 April 2006, 06:00 UTC. The shown profiles represent averaged fluxes between $\mathrm{x}=35 \mathrm{~km}$ and $\mathrm{x}=65 \mathrm{~km}$ in Fig. 10 .

\subsection{Generation mechanism}

In order to show that the characteristics of the short-wavelike perturbations in the UTLS described above are associated with shear instability, a 2-D idealized simulation was carried out using a two-dimensional Boussinesq version of the 3-D anelastic spectral model presented in Mahalov et al. (2007). The domain is $100 \mathrm{~km}$ wide with periodic boundary conditions in the horizontal, and $15 \mathrm{~km}$ deep extending from $5 \mathrm{~km}$ to $20 \mathrm{~km}$ in altitude. The background potential temperature and horizontal wind profiles used in the idealized simulation are shown in Fig. 12a. These profiles are obtained from the IOP 8 microscale model run after locally smoothing out the short-wavelike fluctuations and keeping the primary mountain wave. The Richardson number calculated from these profiles shows that the necessary condition for $\mathrm{KHI}$ ( $\mathrm{Ri} \leq$ 0.25 ) is satisfied in the altitude range between 12 and $13 \mathrm{~km}$ (Fig. 12b). Consequently, the idealized model simulation is initialized by adding a very small random perturbation to the background temperature profile. Figure 13a shows a vertical cross section of potential temperature and vertical velocity from the idealized simulation. The corresponding cross section from the real-data IOP 8 microscale simulations is shown in Fig. 13b. It should be noted that the intent here is not to reproduce the exact structure obtained in the real-data simulation but to investigate the shear instability as a possible generation mechanism for the short-wavelike fluctuations; the shear layer from the real-data simulation is slightly tilted reflecting the upstream tilt of the mountain wave, whereas the temperature and the wind used in the idealized simulation depend on the altitude only. The horizontal wavelength of short-wavelike perturbations in the idealized simulation results is $\lambda \approx 6.7 \mathrm{~km}$ (Fig. 13a), which compares well with that found in the real-data IOP 8 simulation. Also, the structure of potential temperature and vertical velocity perturbations, and the orientation of phase lines of vertical velocity in the idealized simulation results (Fig. 13a) are similar to those in the real-data simulation (Fig. 13b). Furthermore, the vertical profiles of heat and momentum fluxes obtained from the idealized model run (Fig. 14) show strong divergence near the maximum of the wind shear $(z \approx 12 \mathrm{~km})$ with signs and shapes that are in remarkable agreement with those obtained for the real case simulation (Fig. 11). Since the only mechanism present in the idealized case is the shear instability, we conclude that the short-wavelike fluctuations observed in the UTLS region are due to Kelvin-Helmholtz instability.

\section{Distributions of $\mathrm{O}_{3}, \mathrm{CO}$, temperature and vertical ve- locity observed in UTLS during IOP 6}

\subsection{Comparison between simulations and observations}

Further validation of the model is provided by the comparison of aircraft measurements and model-simulated potential 

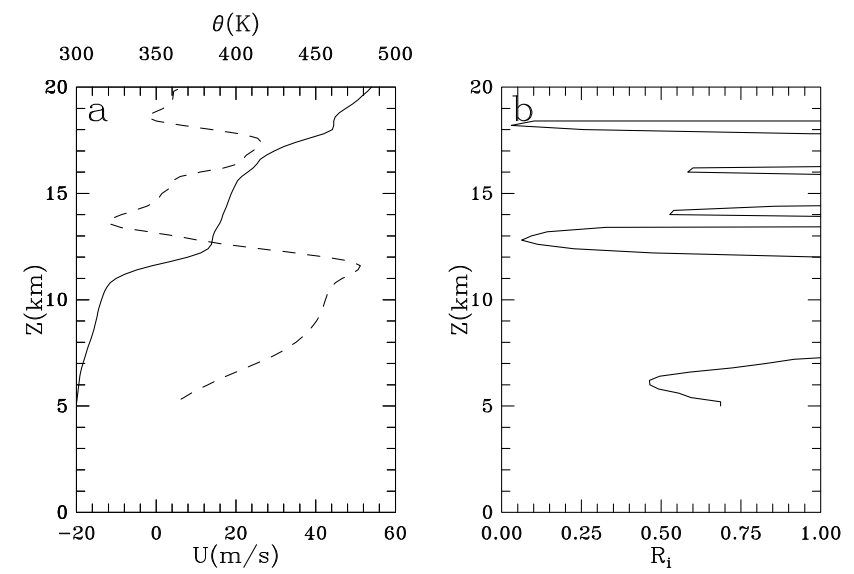

Fig. 12. (a) Vertical profiles of potential temperature (solid) and eastward wind component (dashed) used to initialize the idealized simulation (see text). These profiles are obtained from the microscale model simulation on 1 April 2006, 06:00 UTC at location $x=50 \mathrm{~km}$ in Fig. 10 after smoothing out the short-wave fluctuations. (b) The corresponding vertical profile of Richardson number.

temperature, vertical velocity, eastward and northward wind components along a large portion of the NSF/NCAR G-V track during IOP 6 on 25 March 2006 (Figs. 15a-c). The fields simulated by the microscale model have been interpolated in time and space to the path of the aircraft. The selected portion of the aircraft flight is about $5.5 \mathrm{~h}$ long and was flown between 12 and $13 \mathrm{~km}$ in altitude in the lower stratosphere along the racetrack pattern (cf. Fig. 3d). Pronounced and regular fluctuations - signatures of mountain waves - are evident in all fields. The vertical velocity shows updrafts and downdrafts up to $\pm 6 \mathrm{~m} \mathrm{~s}^{-1}$. The measured and model simulated fields, which are shown in the same panels, show variations with similar amplitudes and wavelengths. Figure 16 shows representative zoom views of vertical velocity field during two sub-period spanning $0.5 \mathrm{~h}$ each. These zooms reveal a high degree of agreement between the simulated and observed fields. Overall, the degree of agreement found in Figs. 1 and $15-16$ is encouraging and represents a good validation of the microscale model.

\subsection{Impact of vertical velocity and gradients on short fluctuations of $\mathrm{O}_{3}$ and $\mathrm{CO}$}

\subsubsection{Variations in the amplitudes of $\mathrm{O}_{3}$ and $\mathrm{CO}$}

Figure 17 compares observed variations of vertical velocity (Fig. 17a); and $\mathrm{O}_{3}, \mathrm{CO}$ and potential temperature (Fig. 17b) along the same portion of the aircraft flight as in (Fig. 16b). In order to find the location of the air masses sampled by the aircraft with respect to the tropopause, we estimated the level of the tropopause from the microscale simulations. We define the tropopause by the jump of the Brunt Vaisala frequency $(N)$. The black curve superimposed in Fig. 18
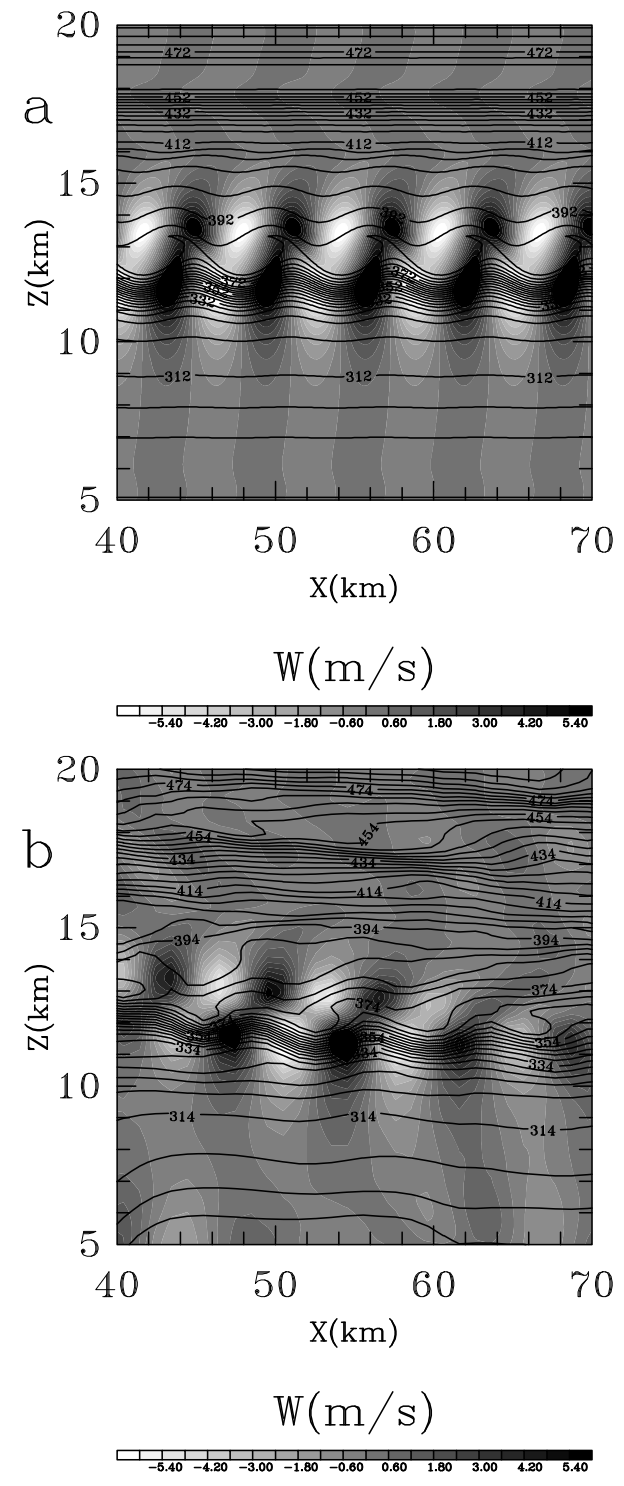

Fig. 13. Vertical cross-sections of potential temperature (contours, $\mathrm{K}$ ) and vertical velocity (grey scale, $\mathrm{m} \mathrm{s}^{-1}$ ) from (a) idealized simulation after $30 \mathrm{~min}$ of integration, and (b) microscale model realdata simulation on 1 April 2006, 06:00 UTC. The baseline of the cross-section in (b) is a segment of dashed line III from Fig. 3d.

presents the vertical profile of $N^{2}$ as a function of potential temperature from the model results. This profile is averaged over the horizontal. It shows a strong jump in the value of the stability at the vertical level of $330 \mathrm{~K}$ (the horizontal dashed line in Fig. 18). This level also coincides with the level where the vertical gradients of $\mathrm{O}_{3}$ and $\mathrm{CO}$ increase, indicating that the tropopause is located around 330 $\mathrm{K}$. The air masses sampled by the aircraft during the leg presented in Fig. 17 have potential temperature values above $330 \mathrm{~K}$. This suggests that most of the air masses sampled were located above the tropopause. Overall, the amplitudes of the short fluctuations in $\mathrm{O}_{3}$ and $\mathrm{CO}$ follow the amplitudes 


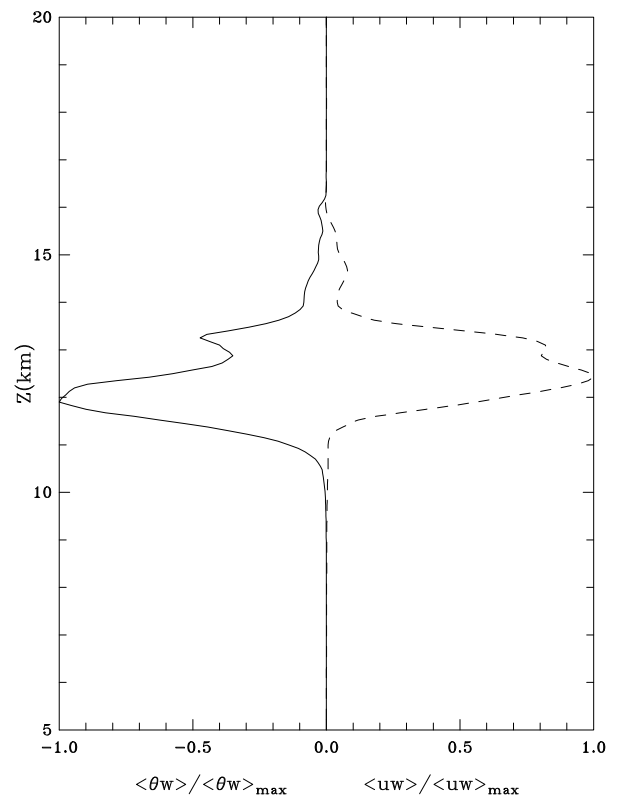

Fig. 14. Vertical profiles of momentum (dashed) and heat (solid) fluxes from the idealized simulation. The shown profiles represent horizontally averaged fluxes.

observed in vertical velocity (Fig. 17). For example, around times $2.5 \mathrm{~h}$ and $2.8 \mathrm{~h}$, the magnitude of vertical velocity is more than $4 \mathrm{~m} / \mathrm{s}$, and the amplitudes of the short fluctuations observed in $\mathrm{O}_{3}$ and $\mathrm{CO}$ around these times are also higher compared to those found at other times (i.e. around $2.6 \mathrm{~h}$ ). The amplitudes of the short fluctuations in $\mathrm{O}_{3}$ and $\mathrm{CO}$ vary along the path of the flight. They are relatively high between $2.3 \mathrm{~h}$ and $2.52 \mathrm{~h}$, and between $2.74 \mathrm{~h}$ and $2.80 \mathrm{~h}$ (note that the amplitude of $\mathrm{CO}$ between $2.74-2.80 \mathrm{~h}$ is smaller than that found between $2.30-2.52 \mathrm{~h}$ ); and are small between times 2.52-2.74h, where the vertical velocity also shows values with small magnitudes. A closer look to Figs. 17a-b reveals, however, that there are flight times where the amplitude of $\mathrm{O}_{3}$ and $\mathrm{CO}$ do not follow those of vertical velocity. For instance, around times $2.38 \mathrm{~h}$ and $2.68 \mathrm{~h}$, the magnitude of vertical velocity have comparable values that are between $1 \mathrm{~m} / \mathrm{s}$ and $2 \mathrm{~m} / \mathrm{s}$. On the other hand, the amplitude of the fluctuations found in $\mathrm{CO}$ and $\mathrm{O}_{3}$ at $2.68 \mathrm{~h}$ are very small compared to those present at $2.38 \mathrm{~h}$. This suggests that, although the vertical motion induced by waves is responsible for the fluctuations found in the tracers, the variation of the amplitude of vertical motion observed along the flight track does not explain by itself the variation of the amplitudes seen in the fluctuations of tracers.

\subsubsection{Variations in the phases of $\mathrm{O}_{3}$ and $\mathrm{CO}$}

Comparison between the phases observed in the short fluctuations of $\mathrm{O}_{3}$ and potential temperature (Fig. 17b) reveals that $\mathrm{O}_{3}$ and potential temperature have same phases, and
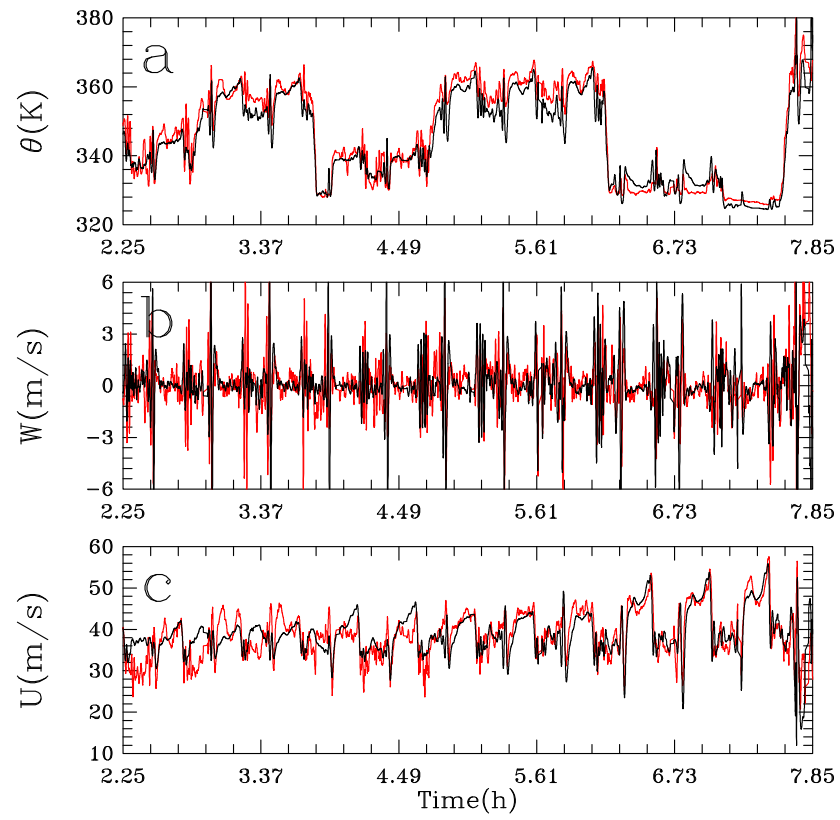

Fig. 15. Comparison between the aircraft observations (red) and microscale model simulation (solid) of (a) potential temperature, (b) vertical velocity, (c) eastward wind component along the racetrack path of the HIAPER aircraft during T-REX IOP 6 (cf. Fig. 3d). The time is relative to 25 March 2006, 15:00 UTC. Shown is a $5.5 \mathrm{~h}$ portion of the flight during which the aircraft completed several racetracks at altitudes between 12 and $13 \mathrm{~km}$ m.s.l.

are positively correlated between $2.30 \mathrm{~h}$ and $2.52 \mathrm{~h}$. Beyond flight times of $2.52 \mathrm{~h}$, the relationship between these phases changes sign, and the correlation between $\mathrm{O}_{3}$ and potential temperature becomes negative. On the average, the phase relationship between the short fluctuations of $\mathrm{CO}$ and potential temperature shows negative correlation with higher amplitudes for times less than $2.52 \mathrm{~h}$. The correlations are not well defined beyond $2.52 \mathrm{~h}$ because the amplitude of $\mathrm{CO}$ is much smaller.

\subsubsection{The role of the vertical gradients}

As shown above the vertical motion does not explain by itself the changes in amplitudes and phases of $\mathrm{O}_{3}$ and $\mathrm{CO}$. Previous studies have shown that the fluctuations of tracers produced by the vertical motion in the presence of gravity waves depends on the vertical mean gradients of tracers (Moustaoui et al., 2010, Teitelbaum et al., 1996, Moustaoui, et al., 1999). We therefore expect the mean gradients of $\mathrm{O}_{3}$ and $\mathrm{CO}$ to change in magnitude along the portion of the flight presented in Figs. $17 \mathrm{a}-\mathrm{b}$. The mean gradient of $\mathrm{O}_{3}$ is also expected to change sign along the same portion in order to account for the reversal of phases and correlations between $\mathrm{O}_{3}$ and potential temperature. Figure 18 shows the mean vertical profiles of $\mathrm{O}_{3}$ and $\mathrm{CO}$ derived from the aircraft measurements. The way these profiles were calculated is described in detail 

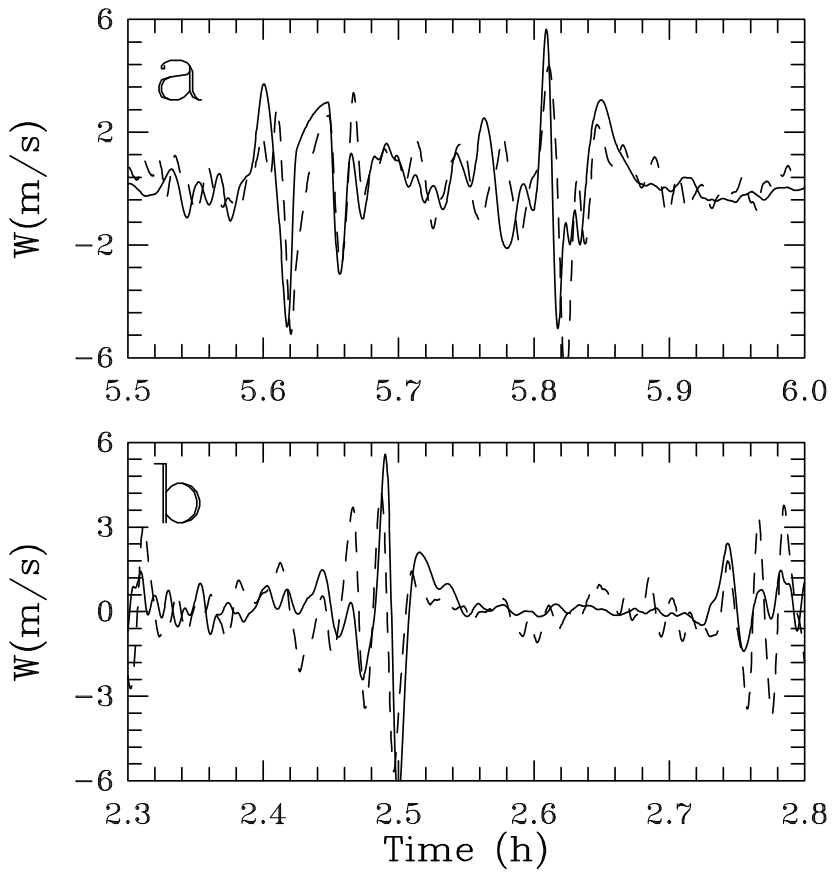

Fig. 16. As in Fig. 15 but for vertical velocity zoomed on two segments of the flight: (a) $5.5 \mathrm{~h}-6 \mathrm{~h}$, and (b) $2.3 \mathrm{~h}-2.8 \mathrm{~h}$. The time is relative to 25 March 2006, 15:00 UTC.

in Moustaoui et al. (2010). Here we give a brief explanation. The mean profiles of $\mathrm{O}_{3}$ and $\mathrm{CO}$ are obtained by collecting each individual value of ozone, $\mathrm{CO}$ and potential temperature from the observations during the entire flight. Then, for each value of potential temperature, the collected values of $\mathrm{O}_{3}$ and $\mathrm{CO}$ are averaged. The resulting $\mathrm{O}_{3}$ and $\mathrm{CO}$ profiles are then smoothed using a running mean to obtain the mean $\mathrm{O}_{3}$ and $\mathrm{CO}$ profiles presented in Fig. 18.

The mean $\mathrm{O}_{3}$ have a positive gradient between $330 \mathrm{~K}$ and $342 \mathrm{~K}$, and negative gradient within a layer between $342 \mathrm{~K}$ and $356 \mathrm{~K}$. The mean gradient of $\mathrm{CO}$ shows high negative value below $342 \mathrm{~K}$, and small values above $342 \mathrm{~K}$. Looking back to Fig. 17b, for times between $2.30 \mathrm{~h}-2.52 \mathrm{~h}$, the average potential temperature is between $330 \mathrm{~K}$ and $342 \mathrm{~K}$. The gradients seen by the flight are positive for $\mathrm{O}_{3}$ and negative with large magnitude for $\mathrm{CO}$ (Fig. 18). The vertical motion induced by the short waves is then expected to produce fluctuations of $\mathrm{O}_{3}(\mathrm{CO})$ with relatively high amplitudes that are positively (negatively) correlated with potential temperature. This explains the behavior observed in the fluctuations of $\mathrm{O}_{3}$ and $\mathrm{CO}$ for times between 2.30 and 2.52 (Fig. 17b). On the other hand, beyond flight times of $2.52 \mathrm{~h}$, the potential temperature is on the average between $340 \mathrm{~K}$ and $350 \mathrm{~K}$ where the mean gradient of $\mathrm{O}_{3}$ is negative, and where that of $\mathrm{CO}$ is small (Fig. 18). The waves evolving in these gradients will then produce fluctuations with negative correlations for $\mathrm{O}_{3}$ and small amplitudes for CO. This behavior is also clearly seen in $\mathrm{O}_{3}$ and $\mathrm{CO}$ fluctuations. Thus our explanation for
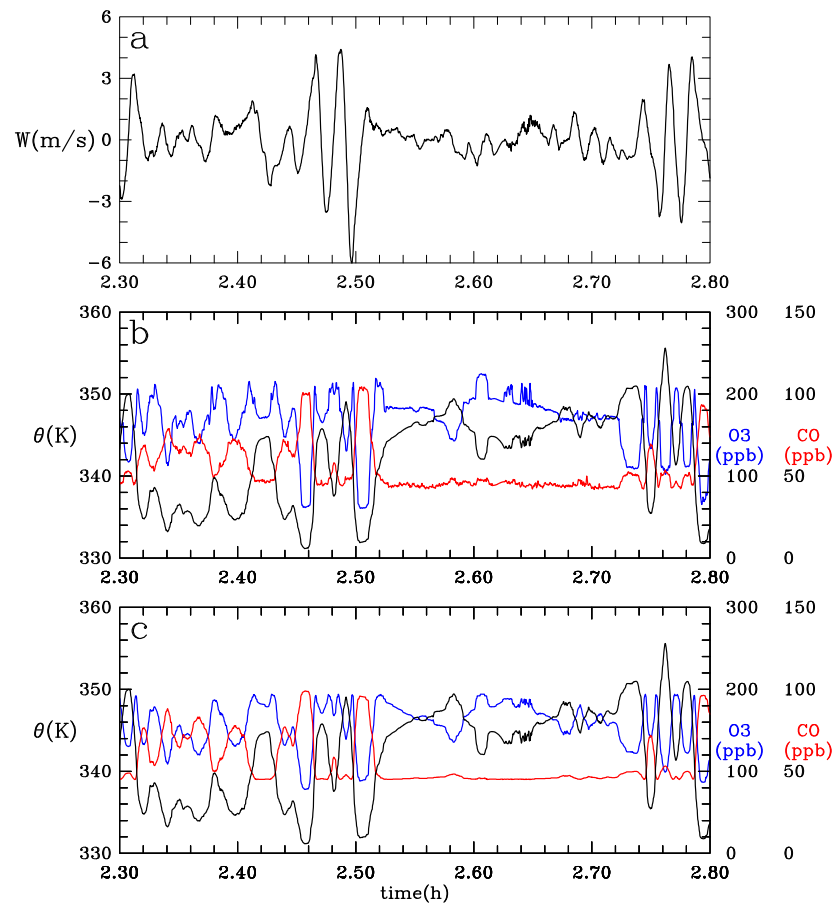

Fig. 17. Variations of (a) vertical velocity (b) ozone (blue) and $\mathrm{CO}$ (red) observed along $2.3 \mathrm{~h}-2.8 \mathrm{~h}$ segment of the flight; (c) is the same as (b) except that the variations are reconstructed from observed potential temperature and the mean gradients of $\mathrm{O}_{3}$ and $\mathrm{CO}$. The observed potential temperature is superimposed in (b) and (c).

the variations of amplitudes and phases, and the role of the vertical motion and the mean gradients is supported by the observations.

To further confirm the above explanation, the variations of $\mathrm{O}_{3}$ and $\mathrm{CO}$ are reconstructed from those of potential temperature shown in Fig. 17b and from the smoothed mean profiles of these tracers presented in Fig. 18. For each observed value of potential temperature along the portion of the flight, we calculate $\mathrm{O}_{3}$ and $\mathrm{CO}$ corresponding to that value from the mean profiles (Fig. 18). The resulting reconstructed fluctuations of $\mathrm{CO}$ and $\mathrm{O}_{3}$ are presented in Fig. 17c. These profiles are in good agreement with those observed along the aircraft path . The observed changes in amplitudes and phases of $\mathrm{O}_{3}$ and $\mathrm{CO}$ (Fig. 17b) are very well reproduced (Fig. 17c). The correlations between reconstructed and the observed variations are 0.91 for $\mathrm{O}_{3}$, and 0.91 for $\mathrm{CO}$. Thus, the reconstructed variations support our explanation of the behavior of the fluctuations observed in $\mathrm{O}_{3}$ and $\mathrm{CO}$, and confirm the role of both the vertical motion and the mean gradients on the distributions of these tracers. 


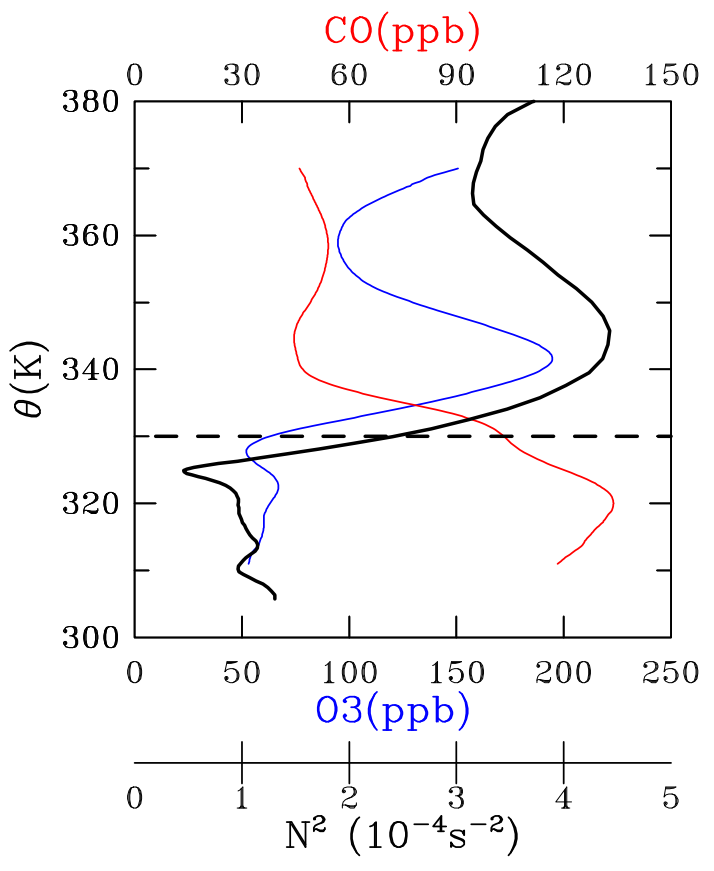

Fig. 18. Mean vertical profiles of $\mathrm{O}_{3}$ (blue) and $\mathrm{CO}$ (red) as a function of potential temperature derived from the aircraft measurements, and the mean vertical profile of the square of the Brunt Vaisala frequency (black) calculated from the model simulations.

\section{Conclusions}

In this paper we presented results of high-resolution simulations of mountain waves under real atmospheric conditions documented during two Intense Observational Periods (IOP 6 and IOP 8) of the Terrain-induced Rotor Experiment (TREX). We particularly focus on mountain waves in the upper troposphere and lower stratosphere (UTLS). Refined vertical gridding has been developed and applied within a microscale model that is driven by data from the finest domain of the WRF model. In the vertical, this refined grid had 181 points with a significantly improved resolution in the UTLS region. This number of grid points in the vertical is significantly higher than the number of vertical levels typically used in NWP models.

Comparisons of in situ radiosonde and aircraft observations obtained during the two T-REX IOPs with fields simulated by the microscale model show favorable agreement with comparable wavelengths and amplitudes of perturbations related to the primary mountain wave as well as the secondary short perturbations in the UTLS. For the comparison the model simulated fields were interpolated in space and time to the radiosonde trajectories as well as to the flight path of the HIAPER aircraft. The degree of agreement between the microscale model simulations and the observations is encouraging given the difficulty in accurately predicting the exact timing and location of small-scale features such as those associated with secondary perturbations in the UTLS and given many uncertainties related to initial conditions, interpolation of simulation results to the positions of measurements, phase lag between the simulated and observed disturbances, etc. Despite all these limitations, the comparisons between the simulation results and observations is more than reasonable and provides a solid verification for the microscale model.

We showed that the vertical grid refinement, achieved in this study with the use of the microscale model, is critical for resolving small-scale perturbations in UTLS and for numerically simulating dynamical processes that lead to their generation. Horizontal nesting alone was proved to be insufficient for this purpose. Furthermore, the increased vertical resolution afforded by the vertical grid refinement was proved also to be beneficial for resolving the inversion layer related to the trapped lee waves at lower tropospheric levels. Furthermore, we showed that the secondary short perturbations in UTLS form in regions of strong vertical wind shear and cause a reversal of momentum fluxes there. The vertical wind shear owes its origin to vertically propagating mountain waves originating from the lower troposphere. The spectral properties of these short fluctuations in UTLS and the attendant vertical profiles of heat and momentum fluxes show that they are generated by Kelvin-Helmholtz instability along shear lines locally induced by the primary mountain wave. The idealized numerical simulation carried out using real temperature and wind profiles obtained from the microscale simulation confirmed that the short perturbations, despite visual resemblance, are not trapped gravity waves but instead small-scale wave motions resulting from KelvinHelmholz instability. We also showed that the variations found in the magnitude of vertical velocity do not explain alone those observed in the amplitudes of $\mathrm{O}_{3}$ and $\mathrm{CO}$, even though the latter are produced by the vertical motion induced by mountain waves. We showed that the combination of both the vertical motion and the local vertical gradients of $\mathrm{O}_{3}$ and $\mathrm{CO}$ account for the modulations of amplitudes and phases found in the variations of these tracers.

Finally, while the grid refinement provided by the microscale model in this study allowed resolution of certain scales of shear instability, the full dynamics of perturbations at these scales remains constrained by the allowable resolution and the subgrid-scale parametrization. Much higher resolution, in both the horizontal and vertical directions, is needed to fully resolve fine turbulence scales associated with shear instability.

Acknowledgements. This work is sponsored in part by AFOSR contract FA9550-08-1-0055 and by the NSF CMG grant ATM-0934592 to the Arizona State University; and NSF grant ATM-0524891 to the Desert Research Institute which provided support to VG in early stages of this work. We thank the WRF group at NCAR for providing the WRF code. The outstanding efforts of the T-REX field campaign participants and the T-REX staff are greatly appreciated. We are thankful to T. L. Campos for $\mathrm{CO}$ data and I. B. Pollack for $\mathrm{O}_{3}$ data. 
Edited by: A. J. G. Baumgaertner

\section{References}

Alexander, M. J. and Teitelbaum, H.: Observation and analysis of a large amplitude mountain wave event over the Antarctic peninsula, J. Geophys. Res., 112, D21103, doi:10.1029/2006JD008368, 2007.

Bacmeister, J. T. and Schoeberl, M. R.: Breakdown of vertically propagating two-dimensional gravity waves forced by orography, J. Atmos. Sci., 46, 2109-2134, 1989.

Danielsen, E. F., Hipskind, R. S. Starr, W. L. Vedder, J. F. Gaines, S. E. Kley, D., and Kelly K. K.: Irreversible transport in the stratosphere by internal waves of short vertical wavelength, J. Geophys. Res., 96, 17433-17452, 1991.

Dornbrack, A., Birner, T., Fix, A., Flentje, H., Meister, A., Schmid, H., Bromwell, E., and Mahoney, M.: Evidence for intertia gravity waves forming polar stratospheric clouds over Scandinavia, J. Geophys. Res., 107, 8287, doi:10.1029/2001JD000452, 2002.

Dornbrack, A.: Turbulent mixing by breaking gravity waves, J. Fluid Mech., 375, 113-141, 1998.

Doyle, J., Shapiro, M., Jiang, Q., and Bartels, D.: Large-amplitude mountain wave breaking over Greenland, J. Atmos. Sci., 62, 3106-3126, 2005.

Fritts, D. C. and Alexander, M. J.: Gravity wave dynamics and effects in the middle atmosphere, Rev. Geophys., 41(1), 1003, doi:10.1029/2001RG000106, 2003.

Grubišić, V. and Billings, B. J.: The intense lee-wave rotor event of Sierra Rotors IOP 8, J. Atmos. Sci., 64, 4178-4201, 2007.

Grubišić, V. and Billings, B. J.: Climatology of the Sierra Nevada mountain-wave events, Mon. Weather Rev., 136, 757-768, 2008.

Grubišić, V., Doyle, J. D., Kuettner, J., Mobbs, S., Smith, R. B., Whitman, D., Dirks, R., Czyzyk, S., . Cohn, S. A, Vosper, S., Weissmann, M., Haimov, S., De Wekker, S. J. F., Pan, L. L., and Chow, F. K.: The Terrain-induced Rotor Experiment: A field campaign overview with some highlights of special observations, B. Am. Meteorol. Soc., 89, 1513-1533, 2008.

Hamming, R. W.: Digital filters, Englewood Cliffs, NJ, USA, Prentice-Hall, 257 pp., 1983.

Hoffmann, P., Serafimovich, A., Peters, D., Dalin, P., Goldberg, R., and Latteck, R.: Inertia gravity waves in the upper troposphere during the MaCWAVE winter campaign - Part I: Observations with collocated radars, Ann. Geophys., 24, 2851-2862, doi:10.5194/angeo-24-2851-2006, 2006.

Joseph, B., Mahalov, A., Nicolaenko, B., and Tse, K. L.: Variability of turbulence and its outer scales in a nonuniformly stratified tropopause jet, J. Atmos. Sci., 41, 524-537, 2004.

Kirkwood, S., Mihalikova, M., Rao, T. N., and Satheesan, K.: Turbulence associated with mountain waves over Northern Scandinavia - a case study using the ESRAD VHF radar and the WRF mesoscale model, Atmos. Chem. Phys., 10, 3583-3599, doi:10.5194/acp-10-3583-2010, 2010.

Klemp, J. B., Dudhia, J., and Hassiotis, A.: An upper gravity wave absorbing layer for NWP applications, Mon. Weather Rev., 136, 3987-4004, 2008.

Lane, T. P. and Sharman, R. D.: Gravity wave breaking, secondary wave generation, and mixing above deep convection in a three-dimensional cloud model, Geophys. Res. Lett., 33, doi:10.1029/2006GL027988, 2006.
Laprise, R.: The Euler equations of motion with hydrostatic pressure as an independent variable, Mon. Weather Rev., 120, 197207, 1992.

Lott, F., and Teitelbaum, H.: Nonlinear dissipative critical level interaction in a stratified shear flow: instabilities and gravity waves, Geophys. Astro. F. Dynam., 66, 133-167, 1992.

Lilly, D. K.: On the instability of Ekman boundary flow, J. Atmos. Sci., 23, 481-494, 1966.

Mahalov, A. and Moustaoui, M.: Vertically nested non-hydrostatic model for multi-scale resolution of flows in the Upper Troposphere and Lower Stratosphere, J. Comp. Phys., 228, 1294-1311, 2009.

Mahalov, A. and Moustaoui, M.: Characterization of atmospheric optical turbulence for laser propagation, Laser Photon. Rev., 4, 144-159, doi:10.1002/lpor.200910002, 2010.

Mahalov, A., Moustaoui, M., Nicolaenko, B., and Tse, K. L.: Computational studies of inertia-gravity waves radiated from upper tropospheric jets, Theor. Comput. Fluid. Dynam., 21, 399-422, 2007.

Mahalov, A., Moustaoui, M., and Nicolaenko, B.: 3D Instabilities in shear stratified non-parallel flows, Kin. Related Model., 2, 215-229, 2009.

Moustaoui, M., Teitelbaum, H., Van Velthoven, P. F. J., and Kelder, H.: Analysis of gravity waves during the POLINAT experiment and some consequences for stratosphere-troposphere exchange, J. Atmos. Sci., 56, 1019-1030, 1999.

Moustaoui, M., Joseph, B., and Teitelbaum, H.: Mixing layer formation near the tropopause due to gravity wave-critical level interactions in a cloud-resolving model, J. Atmos. Sci., 61, 31123124, 2004.

Moustaoui, M., Mahalov, A., Teitelbaum, H., and Grubišić, V.: Nonlinear modulation of $\mathrm{O}_{3}$ and $\mathrm{CO}$ induced by mountain waves in the upper troposphere and lower stratosphere during terraininduced rotor experiment, J. Geophys. Res., 115, D19103, doi:10.1029/2009JD013789, 2010.

Plougonven, R., Hertzog, A., and Teitelbaum, H.: Observations and simulations of a large-amplitude mountain wave breaking over the Antarctic Peninsula, J. Geophys. Res., 113, D16113, doi:10.1029/2007JD009739, 2008.

Prusa, J. M., Smolarkiewicz, P. K., and Garcia, R. R.: Propagation and breaking at high altitudes of gravity waves excited by tropospheric forcing, J. Atmos. Sci., 53, 2186-2216, 1996.

Satomura, T. and Sato, K.: Secondary generation of gravity waves associated with the breaking of mountain waves, J. Atmos. Sci., 56, 3847-3858, 1999.

Skamarock, W. C. and Klemp, J. B.: A time-split nonhydrostatic atmospheric model for weather research and forecasting applications, J. Comput. Phys., 227, 3465-3485, 2008.

Smith, R. B., Woods, B. K., Jensen, J.,Cooper, W. A. , Doyle, J. D., Jiang, Q., and Grubišić, V.: Mountain waves entering the stratosphere, J. Atmos. Sci., 65, 2543-2562, 2008

Teitelbaum, H., Moustaoui, M., Ovarlez, J., and Kelder, H.: The role of atmospheric waves in the laminated structure of ozone profiles at high latitude, Tellus, 48A, 442-455, 1996.

Teitelbaum, H., Moustaoui, M., Sadourny, R., and Lott, F.: Critical levels and mixing layers induced by convectively generated gravity waves during CEPEX, Q. J. Roy. Meteorol. Soc., 125, 1715-1734, 1999.

Thompson, G., Rasmussen, R. M., and Manning, K.: Explicit 
forecasts of winter precipitation using an improved bulk microphysics scheme. Part 1: Description and sensitivity analysis, Mon. Weather Rev., 132, 519-542, 2004.

Vosper, S. B. and Worthington, R. M.: VHF radar measurements and model simulations of mountain waves over Wales, Q. J. Roy. Meteorol. Soc., 128, 185-204, doi:10.1256/00359000260498851, 2002.
Wang, J., Bian, J., Brown, W. O. J., Cole, H., Grubišić, V., and Young, K.: Vertical air motion from T-REX radiosonde and dropsonde data, J. Atmos. Techol., 26, 928-942, 2009.

Wang, P. K.: Moisture plumes above thunderstorm anvils and their contributions to cross-tropopause transport of water vapor in midlatitudes, J. Geophys. Res., 108, 4194, doi:10.1029/2002JD002581, 2003. 